\title{
Specificity and Combinatorial Effects of Bacillus Thuringiensis Cry Toxins in the Context of GMO Environmental Risk Assessment
}

\author{
Angelika Hilbeck ${ }^{1 *}$ and Mathias Otto ${ }^{2}$ \\ ${ }^{1}$ Department of Environmental Systems Science, Swiss Federal Institute of Technology, Institute for Integrative Biology, \\ Zurich, Switzerland, ${ }^{2}$ Federal Agency for Nature Conservation, Bonn, Germany
}

OPEN ACCESS

Edited by:

Robin Mesnage,

King's College London, UK

Reviewed by:

M. Jahangir Alam,

University of Houston College of

Pharmacy, USA

Yue-Wern Huang,

Missouri University of Science and

Technology, USA

${ }^{*}$ Correspondence:

Angelika Hilbeck

angelika.hilbeck@env.ethz.ch

Specialty section:

This article was submitted to

Environmental Health,

a section of the journal

Frontiers in Environmental Science

Received: 26 August 2015

Accepted: 15 October 2015

Published: 09 November 2015

Citation:

Hilbeck $A$ and Otto M (2015) Specificity and Combinatorial Effects of Bacillus Thuringiensis Cry Toxins in the Context of GMO Environmental Risk Assessment.

Front. Environ. Sci. 3:71. doi: 10.3389/fenvs.2015.00071
Stacked GM crops expressing up to six Cry toxins from Bacillus thuringiensis (Bt) are today replacing the formerly grown single-transgene GM crop varieties. Stacking of multiple Cry toxins not only increase the environmental load of toxins but also raise the question on how possible interactions of the toxins can be assessed for risk assessment, which is mandatory for GM crops. However, no operational guidelines for a testing strategy or testing procedures exist. From the developers point of view, little data testing for combinatorial effects of Cry toxins is necessary as the range of possibly affected organisms focuses on pest species and no evidence is claimed to exist pointing to combinatorial effects on non-target organisms. We have examined this rationale critically using information reported in the scientific literature. To do so, we address the hypothesis of narrow specificity of Cry toxins subdivided into three underlying different conceptual conditions (i) "efficacy" in target pests as indicator for "narrow specificity," (ii) lack of reported adverse effects of Cry toxins on non-target organisms, and (iii) proposed modes of action of Cry toxins (or the lack thereof) as mechanisms underlying the reported activity/efficacy/specificity of Cry toxins. Complementary to this information, we evaluate reports about outcomes of combinatorial effect testing of Cry toxins in the scientific literature and relate those findings to the practice of environmental risk assessment of Bt-crops in general and of stacked Bt-events in particular.

Keywords: Bt toxins, non-target organisms, target organisms, synergistic effects, mode of action, adverse effects

\section{BACKGROUND}

Today, many crop plants have been genetically modified (GM) to contain transgenic DNA sequences from the bacterium Bacillus thuringiensis (Bt) coding for the expression of socalled Cry toxins from 3 to 4 different classes (Cry1, Cry2, Cry3, and to a very limited extent Cry9 class) (Schnepf et al., 1998; Sanchis, 2011; Sansinenea, 2012; van Frankenhuyzen, 2013). These microbial toxins engineered into GM crops plants aim to control certain target pest species which differ depending on the regions where the crops are grown. In Bt plants, the Cry toxins are present persistently and usually in all plants parts from germination to harvest of the crops. Specifically, it is through genetic engineering that also the pollen of GM plants can express these bacterial toxins. Bt-toxins in pollen are not degraded by UV light and remain bioactive when, for example, deposited on host plants 
(Ohlfrest et al., 2002). Toxic pollen is rare in nature as, typically, there is little selective advantage for such a trait to evolve.

When used as sprayable, externally applied B. thuringiensis based insecticides, the risk for non-target organisms to ingest the Cry toxins is low due to the limited persistence of these sprays in space and time as the Bt toxin is quickly degraded by UV light and removed from plants by rain (Behle et al., 1997). Risks to non-target insects are further reduced because sprayable B. thuringiensis products usually consist of Cry toxins in their inactive crystalline form (hence their abbreviation "Cry") that need to undergo a complex activation process before becoming active (see below for details). With the introduction of Cry toxin producing GM crop plants into industrial agricultural systems, a whole new dimension of spatio-temporal exposure to Cry toxins opened up involving a far broader range of non-target organisms below- and above ground (Hilbeck, 2001, 2002). Thus, the potential for chronic longterm effects became more likely to occur than with short-lived, inactive sprayable $B$. thuringiensis insecticides. Consequently, it was with the introduction of Cry toxin producing GM crops that the likelihood of potential adverse effects (i.e., risks) on non-target organisms, in particular beneficial insects like natural enemies of pests, pollinators, and species of conservation concern, came on the research agenda (Hilbeck, 2001, 2002).

Since about one decade, there is a marked increase in the commercial approval and adoption of GM plants carrying multiple transgenes coding for the simultaneous expression of several insecticidal Cry toxins (and also transgenes for herbicide resistance), so called "pyramided" or "stacked" events (Fernandez-Cornejo et al., 2014; United States Department of Agriculture and Economic Research Service (ERS), 2014). In 2014 , stacked GM cotton reached almost $80 \%$ of cotton plantings up from around 25\% 10 years earlier. Stacked GM maize made up $76 \%$ of the planted maize area in 2014 up from less than $10 \%$ a decade ago (Fernandez-Cornejo et al., 2014; United States Department of Agriculture and Economic Research Service (ERS), 2014). Stacking Bt transgenes was triggered by spreading resistance among target pest populations against GM crops expressing only single Cry toxins (Tabashnik et al., 2013). The underlying assumption is that pest species are less likely to develop resistance simultaneously against multiple Cry toxins because of their somewhat different modes of action. Whether or not this assumption will hold true for the currently employed Cry toxins that still share significant similarities in their modes of action (Hernández-Rodríguez et al., 2013) is not subject of our evaluation in this paper but deserves a separate analysis.

In this review, we are concerned with the drastically increased Cry toxin load in stacked or pyramided Bt crop varieties resulting in persistent exposure of a wide range of non-target organisms in terrestrial and aquatic ecosystems. In SmartStax ${ }^{\circledR}$ maize, for example, combining six Cry toxins, maximum amounts of $>250 \mu \mathrm{g} / \mathrm{g}$ fresh weight in leaves, $>90 \mu \mathrm{g} / \mathrm{g}$ fresh weight in roots, and $>150 \mu \mathrm{g} / \mathrm{g}$ fresh weight in pollen was reported (Table 1; Stillwell and Silvanovich, 2007; Phillips, 2008). Potential combinatorial effects of these multiple Cry toxins have been recognized by the European regulatory authorities only few years ago (EFSA, 2010a), and are still intensely discussed by regulators and in the scientific community alike (de Schrijver et al., 2014). Yet, most regulators, including EFSA, still operate under the current controversial paradigm that limits the environmental risk assessment to focusing on the added novel substance only which is tested as single purified protein, produced by microbes, in isolation of the GM plants, following testing schemes developed for the regulatory approval of synthetic insecticides (for more details see Hilbeck et al., 2011). The results of these tests are then used in all risk assessments for Bt crops that express these Cry toxins but irrespective of the GM event (e.g., Garcia-Alonso et al., 2006; Romeis et al., 2008; Dolezel et al., 2011; Hilbeck et al., 2011). Consequently, for stacked GM crop plants combining multiple Cry toxins, developers of GM plants are arguing for minimal regulatory oversight of stacked events, if any at all, on the basis that "previously approved GM events that have been combined by conventional plant breeding and contain GM traits that are not likely to interact in a manner affecting safety should be considered

TABLE 1 | Maximum Cry toxin concentrations $[\mu \mathrm{g} / \mathrm{g}]$ measured in field-grown SmartStax, several US locations in 2006*; FW, fresh weight; DW, dry weight.

\begin{tabular}{|c|c|c|c|c|c|c|c|c|c|c|}
\hline Bt toxin & \multicolumn{2}{|c|}{ Leaves } & \multicolumn{2}{|c|}{ Roots } & \multicolumn{2}{|c|}{ Whole plant } & \multicolumn{2}{|c|}{ Pollen } & \multicolumn{2}{|c|}{ Kernels } \\
\hline Cry2Ab2 & 350 & 60 & 120 & 18 & 80 & 19 & 2.3 & 1.8 & 7.5 & 6.7 \\
\hline Cry1F & 31 & 4.7 & 15 & 2.0 & 16 & 1.9 & 32 & 25 & 7.4 & 6.7 \\
\hline Cry3Bb1 & 490 & 92 & 260 & 31 & 220 & 26 & 24 & 19 & 26 & 23 \\
\hline Cry34Ab1 & 279 & 42 & 150 & 19 & 196 & 23 & 117 & 90 & 94 & 85 \\
\hline Cry35Ab1 & 158 & 24 & 71 & 9.0 & 82 & 9.6 & 0.5 & 0.4 & 2.3 & 2.0 \\
\hline Total Coleopteran-active Cry & 927 & 158 & 481 & 59 & 498 & 59 & 142 & 109 & 122 & 110 \\
\hline
\end{tabular}

*Source: compilation based on Phillips (2008) and Stillwell and Silvanovich (2007). 
to be as safe as their conventional counterparts" [Pilacinski et al., 2011, similar arguments by Raybould et al. (2012) and CropLife International (2015)]. EFSA (2010b) largely follows this view and has approved stacked events based on the above argumentsexemplary statements from an opinion for approval of a stacked event expressing three Cry toxins are as follows:

"The safety of Cry1A.105 and Cry2Ab2 proteins expressed in maize MON 89034, the Cry1F and PAT proteins expressed in maize 1507, and the CP4 EPSPS and CP4 EPSPS L214P proteins expressed in maize NK603 have been assessed for their safety previously and no safety concerns were identified for humans and animals... the EFSA GMO Panel considers it unlikely that interactions between the single maize events will occur that may impact on the food and feed safety and nutritional pro perties." [excerpts from EFSA (2010b)-similar justifications and wording has been used in other approvals of stacked events].

In this paper, we examine the two claims that serve as justification to minizime or omit the testing of combinatorial effects of multiple Cry toxins expressed in stacked GM Bt crop plants: (1) Due to narrow specificity of Cry toxins, no species outside of the primary class of target pest organisms are affected and (2) as long as single Cry toxins do not elicit adverse effects, they will not do so in combination with other Cry toxins or other naturally occurring compounds.

Lastly, we will reflect on the regulatory practice of risk assessment of stacked Bt-crops in the EU and will provide recommendations for improvements of the current testing practice.

\section{DEFINITIONS AND DATA USED IN THIS REVIEW}

We carried out a data base search of the Web of Science for peer reviewed international publications in English language for the following key word categories: Category I: "Bacillus thuringiensis" or "Bt" or "toxin" or "protein" combined with Category II: "synergistic" or "interaction" or "combined/combinatorial" "effects." We then selected those studies that reported about in vivo tests only, e.g., bioassays with target and non-target organisms. On occasion, these reports contained also data on in-vitro tests with cell lines that we disregarded for comparability reasons. We restricted our evaluation to studies that reported on combinatorial effects between Cry proteins and some naturally occuring plant-, bacteria-, or insect-compounds as they can be encountered by non-target organisms feeding on stacked GM Bt plants in their natural environment. Studies on combinatorial or complementary effects with herbicides and other pesticides, such as neonicotinoid residues (Douglas and Tooker, 2015), have been omitted and left for future evaluations. In Table 2, we compiled the selected key reports to allow for a quick overview of the involved compounds, test organisms, and proposed mechanisms.

We report our findings according to the claims outlined above. The definitions for various types of combinatorial effects followed those by Tabashnik (1992):

Synergistic effects in the context of this paper entails effectse.g., mortality rates-of combined toxins exceeding those found for the individual toxin with the highest activity. If synergistic effects occur, this means that the toxicity of a mixture cannot be predicted from the individual ingredients.

Antagonistic effects in the context of this paper are effects contrasting synergistic effects: when a mixture of toxins leads to less toxicity than found for individual toxins with the lowest activity. If potency is less than expected.

Additive effects in the context of this paper entail effectse.g., mortality rates-of combined toxins not exceeding those found for the individual toxin with the highest activity. If additive effects occur, this means that the toxicity of a mixture could be predicted from the individual ingredients.

\section{RESULTS}

The first claim of narrow specificity rests on two premises: (i) "efficacy" determined in economically important target pests is a reliable indicator for "narrow specificity" of Cry toxins, and (ii) the mode of action of Cry toxins supports the claim of narrow specificity. In the following, we will evaluate the data base for these two premises.

Furthermore, we will summarize the scientific literature documenting effects of single and multiple combined Cry toxins and their postulated mechanisms to examine whether the reported data and methodologies confirm the conclusion of predictability (likelihood) of combinatorial effects.

\section{NARROW SPECIFICITY OF Bt PROTEINS}

Since the claimed narrow specificity of Bt toxins serves as the first line of justification to forego the testing of non-target organisms, the premises this claim rests upon should be well-supported with scientific evidence. Below, we, firstly, scrutinize the current definition of specificity and its application within risk assessment of Bt-crops and non-target organisms. Secondly, we summarize the current state of knowledge regarding the proposed mode of action of Cry toxins.

\section{Assumptions vs. Evidence}

$B$. thuringiensis bacteria express and deposit a multitude of proteineous, insecticidal toxins in various crystalline forms in the bacterial mother cell (called Cry proteins). When the insecticidal properties of these deposited Cry proteins were discovered a century ago, very quickly their potential utility for pest control was recognized and research and development of $B$. thuringiensis based sprayable insecticides began. Today, several commercial $B$. thuringiensis based insecticide formulations are broadly available commercially and used in organic crop production as one of the few permitted sprayable insecticides. Hence, ever since their discovery, research and development efforts have focused almost exclusively on studying their efficacy on economically important, herbivorous pest species (e.g., Hoefte and Whiteley, 1989; Schnepf et al., 1998; Sanchis, 2011; van Frankenhuyzen, 2013). Naturally, for practical pest control purposes, the most efficacious B. thuringiensis-produced Cry proteins are considered to be those that induce maximum -if possible $100 \%$-mortality in a given target pest population with the least amount of toxin 
TABLE 2 | Some key publications highlighting different types of combinatorial effects on insects reported in the scientific literature.

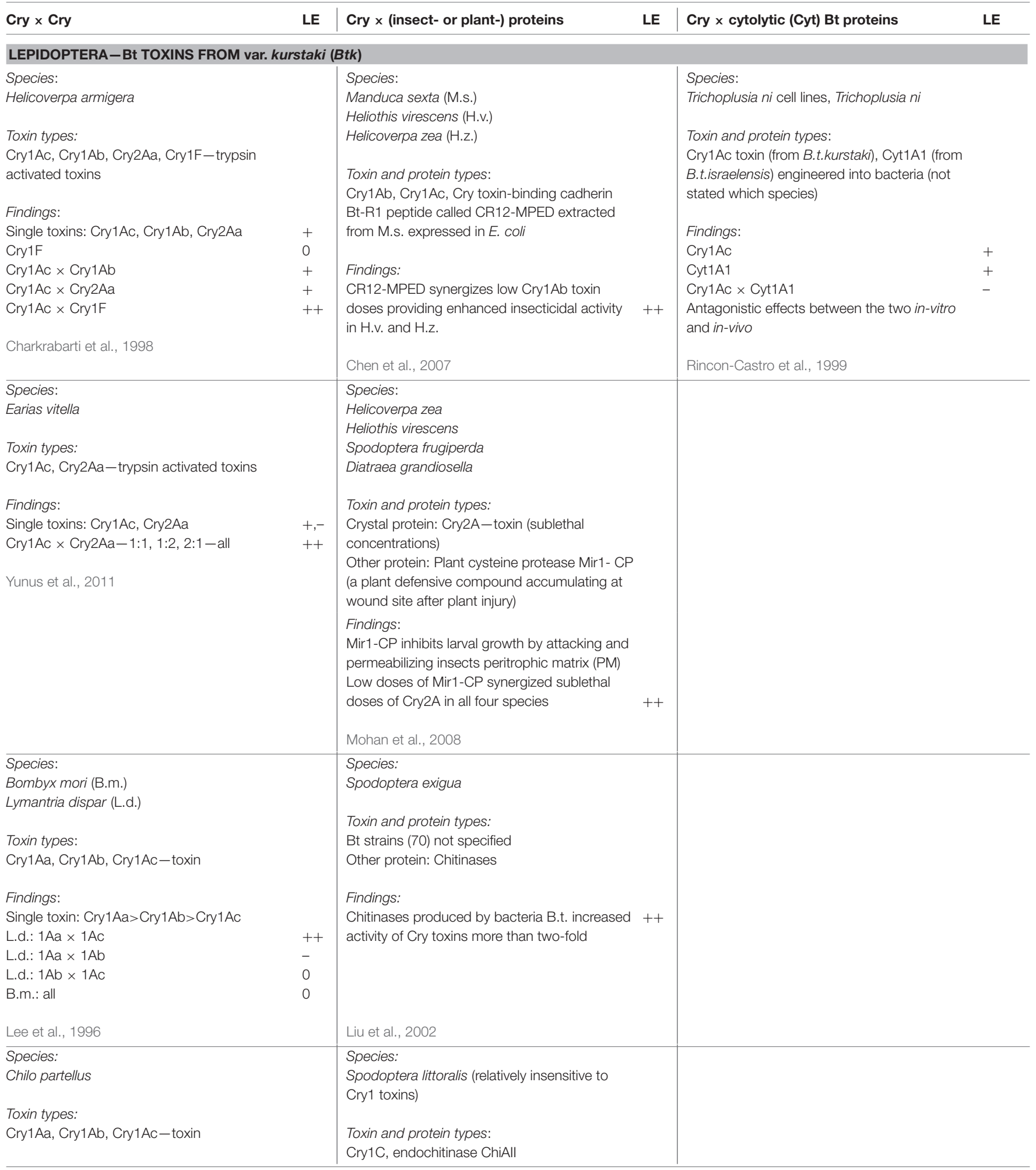




\section{TABLE 2 | Continued}

\begin{tabular}{|c|c|c|c|c|c|}
\hline Cry $\times$ Cry & LE & Cry $\times$ (insect- or plant-) proteins & LE & Cry $\times$ cytolytic (Cyt) Bt proteins & LE \\
\hline $\begin{array}{l}\text { Species: } \\
\text { Helicoverpa armigera, Earias insulana } \\
\text { Toxin types: } \\
\text { Cry1Ac, Cry2Ab, Cry1Fa-trypsin-activated } \\
\text { toxins } \\
\text { Findings: } \\
\text { Cry1Ac-H.a., E.i. } \\
\text { Cry2Ab-H.a., E.i. } \\
\text { Cry1Fa-H.a., E.i. } \\
\text { Cry1Ac } \times \text { Cry2Ab-H.a., E.i. } \\
\text { Cry1Ac } \times \text { Cry1Fa-H.a., E.i. } \\
\text { Ibargutxi et al., } 2008\end{array}$ & $\begin{array}{l}+,+ \\
+,+ \\
0,+ \\
++,+ \\
+,+\end{array}$ & & & & \\
\hline $\begin{array}{l}\text { Species: } \\
\text { Aedes aegypti, Anopheles stephensi, Culex } \\
\text { pipens }\end{array}$ & & & & $\begin{array}{l}\text { Species: } \\
\text { Culex quinquefasciatus, Aedes aegypti }\end{array}$ & \\
\hline
\end{tabular}


TABLE 2 | Continued

\begin{tabular}{|c|c|c|c|c|c|}
\hline Cry x Cry & LE & Cry $\times$ (insect- or plant-) proteins & LE & Cry $x$ cytolytic (Cyt) Bt proteins & LE \\
\hline & & & & $\begin{array}{l}\text { Species: } \\
\text { Culex quinquefasciatus } \\
\text { Toxin and protein types: } \\
\text { CrylVD crystal protoxins } \\
\text { CytA toxin } \\
\text { Both co-transformed into B. thuringiensis } \\
\text { bacteria } \\
\text { Findings: } \\
\text { CrylVD } \\
\text { CytA } \\
\text { CrylVD } \times \text { CytA (co-expressed in Bt) } \\
\text { Chang et al., } 1993\end{array}$ & $\begin{array}{l} \\
\\
\\
\\
\\
+ \\
+ \\
++ \\
+\end{array}$ \\
\hline & & & & $\begin{array}{l}\text { Species: } \\
\text { Culex quinquefasciatus (C.q), Aedes aegypti } \\
\text { (A.a.) } \\
\text { Toxin and protein types: } \\
\text { Bti and Bacillus darmstadtiensis (wild-type) } \\
\text { expressed in E. coli; Cry4Ba and Cyt2Aa2 } \\
\text { Findings: } \\
\text { Cry4Ba (C.q., A.a.) } \\
\text { Cyt2Aa2 (C.q., A.a.) } \\
\text { Cry4Ba x Cyt2Aa2 (C.q., A.a.) } \\
\text { Cry4Ba toxins were inactive as single toxin } \\
\text { to C. quinquefasciatus but in combination with } \\
\text { Cyt2Aa2 had strong effect } \\
\text { Promdonkoy et al., } 2005\end{array}$ & $\begin{array}{l} \\
\\
\\
\\
\\
\\
\\
+, 0 \\
+,+ \\
++,++\end{array}$ \\
\hline
\end{tabular}

\section{Species:}

Diabrotica undecimpunctata howardi (D.u.h.),

Diabrotica virgifera virgifera (D.v.v.),

Leptinotarsa decemlineata (L.d.)

Toxin and protein types:

Cry3Aa, Cry3Bb toxins

toxin-binding fragment of cadherin receptor

(CR 8 and 10) expressed in E. coli

Findings:

CR8 and 10 isolated from D.v.v. and expressed in E. coli binds activated Cry3Aa and Cry3Bb toxins and enhances toxicity of both toxins in L.d., D.u.h., and D.v.v. from 3- to 13-fold (synergistically). Indivdually, they did not elicit an effect and Cry3 toxins efficacy was lower and differed when administered alone

Park et al., 2009

LE, Level of effect; "-", antagonistic; "O", neutral; "+", additive (definitions see text). 
ingested in the shortest period of time. We refer to this as the concept of "quick kill." Based on this economically motivated concept of "efficacy," most Cry toxins affect most efficaciously only a relatively narrow range of so called "target" pest species. However, this pest control-focused concept underlies the generalization of narrow specificity of all Cry toxins applied to all non-target species and the assumption that Cry toxins are unlikely to affect other species outside of their range of primary (target) organisms (e.g., Soberón et al., 2009; Sanchis, 2011; Pardo-López et al., 2013).

It was with the introduction of GM crops expressing activated Cry toxins constitutively, meaning in all tissues of the GM plants throughout their entire lifespan, that ecologists urged to revisit the validity of the economic definition of "specificity," or "quick kill," and began testing various Cry toxins on non-pest nontarget organisms (Hilbeck, 2001, 2002). Today, with the vastly expanded spatio-temporal exposure of Cry toxins from GM crop plants, easily also reaching beyond the crop field (Hofmann et al., 2014), the need arose to investigate ecologically relevant adverse effects beyond the narrow scope of a small group of economically relevant herbivores considered pests in crop fields and also beyond the single economic parameter of "quick kill." Ecological parameters including cumulative lethal effects, i.e., "slow kill," and sublethal impacts (e.g., developmental time, weight gain, behavioral changes) have now gained importance. Such effects could cause as severe or even more severe ecological consequences for a terrestrial or aquatic ecosystem as a "quick kill" could.

The most comprehensive data source concerning the specificity of Bt proteins is the Bt Toxin Specificity Database (http://www.glfc.cfs.nrcan.gc.ca/bacillus/; van Frankenhuyzen and Nystrom, 2002). Analyses from this database have been published by van Frankenhuyzen in 2009 and 2013 with a recent update in de Schrijver et al. in 2014. While, originally, Cry toxin activity was assumed to be restricted to the insect order of Lepidoptera, this has successively been expanded to include today up to six arthropod orders for which so-called cross-active Bt toxins have been reported (van Frankenhuyzen, 2013). Notably, today, the most widely employed and studied Cry toxins, such as CrylAb or CrylAc, have been reported to affect species from different insect orders or even phyla (Cry1 Ab: Coleoptera, Lepidoptera, Diptera, Hemiptera; Neuroptera, Trichoptera and Nematoda; Cry1Ac: Lepidoptera, Diptera, Hemiptera). But van Frankenhuyzen (2013) found that only a small fraction (17\%) of Cry toxins have ever been tested with species from more than 1 or 2 insect orders. Despite this restriction to certain tested pest species, approximately $40 \%$ of all Bt toxins tested across two or more orders did show cross-activity (de Schrijver et al., 2014). Yet, even for the most tested lepidopteran-active Cryl toxins, only a little more than one third has ever been experimentally tested outside of that order. In total, van Frankenhuyzen (2013) compiled evidence for cross-activity of $27 \mathrm{Bt}$ toxins and 69 insect taxa. We expect that the number of reported cross-activities will likely rise as more experiments with non-target organisms emerge and the old definition of order-specifity of Bt-toxins (van Frankenhuyzen, 2013; de Schrijver et al., 2014) may no longer be regarded as a functional concept-cross-activity may actually become rather a common phenomenon than an execption, certainly under an ecological definition of "efficacy" or "specificity." Apart from few exceptions, the majority of available data from the van Frankenhuyzen-database rely on mortality as the measured endpoint. However, sub-lethal effects such as growth inhibition, changes in developmental time or other parameters which may affect fitness can be expected to occur at far lower effect-doses than those inducing a "quick kill."

\section{Proposed Mode(s) of Action (Mechanism)}

Much of the claimed specificity of Bt-toxins rests on what is known about the mode of action of Cry toxins from research with this narrow set of herbivorous target pest insects and from studying predominantly one Cry toxin class only, Cry 1. By comparison, modes of action of Cry 3 and Cry 2 toxins have received far less attention (Schnepf et al., 1998; Whalon and Wingerd, 2003; Vachon et al., 2012). Some authors think that specificity rests equally on the solubilization-activation process as on the receptor-binding and pore-formation process (Smouse and Nishiura, 1997), while others postulate specificity to rest mainly on (affinity to) specific receptors (Schnepf et al., 1998). Today, quite a controversy exists over the mode of action of Cry toxins which is owed to the fact that there is less scientific certainty about it today than there was when cry transgenes from B. thuringiensis were first engineered into GM plants roughly 30 years ago. Until about a decade ago, the predominant and most agreed model for the mode of action of Cry proteins (the "classical model") as produced by B. thuringiensis went as follows: ingested, inactive crystalline (Cry) proteins must be solubilized in an insect gut environment with a high $\mathrm{pH}(>10)$. The solubilization of crystalline proteins yields a still inactive socalled full-length protoxin (ca. $130 \mathrm{kDa}$ Cryl class and ca $73 \mathrm{kDa}$ Cry3 class) that requires further biochemical cleavage to produce a small toxic fragment. This toxic fragment (ca. $65 \mathrm{kDa}$ Cry1 class and $55 \mathrm{kDa}$ Cry3 class) then must bind to certain receptors located in the midgut ephithelium and, thereby, induce pore formation (also called ion channel forming) and lysis of the gut resulting in septicemia subsequently killing the insect (Schnepf et al., 1998; Whalon and Wingerd, 2003; Vachon et al., 2012). Different sized fragments of the same Cry class have been shown to exhibit different activities in different ranges of affected insects (Haider and Ellar, 1987). A whole range of membrane binding proteins have been suggested as receptors, including numerous cadherins, aminopeptidases, and alkaline phosphatases as well as glycolipids (Pigott and Ellar, 2007; Sanchis, 2011; Vachon et al., 2012).

Today, additional models for Cry toxin mode of action have been suggested with supporting new data. In a recent review, Vachon et al. (2012) describe and critique three models: the "classical" model, the "sequential binding" model, and the "signaling pathway" model. The first two models have in common that the mode of action of activated Cry toxins hinges on the binding of activated (i.e., cleaved) toxic fragments of the original Cry protein to receptors in the midgut epithelium in insect larvae. The sequential binding model proposes a more complex sequence of events with 
more binding steps involving more receptors and the removal of an alpha helix from the Cry toxin leading to a required oligomerization step of the Cry toxins before inserting into the gut membrane and inducing pore formation in the gut of the insect (Soberon et al., 2012). Consequently, in addition to the cadherin receptors of the "classical" model, which are now called to be "primary" receptors, so called "secondary" receptors, GPI (glycosylphosphatidyl-inositol)-anchored receptors, are suggested to have a significant role in pore formation (Soberón et al., 2009; Soberon et al., 2012; Pardo-López et al., 2013). While in the classical model it was believed that monomeric Cryl toxins can bind to cadherin receptors and induce pore formation, in the sequential model it is proposed that cadherin-bound monomeric Cry1 toxins cause conformational changes favoring proteolytic cleavage that allows the rest of the toxin to oligomerize (JiménezJuárez et al., 2007; Soberon et al., 2012; Vachon et al., 2012). The Cry1 toxin oligomers subsequently bind to the GPI-anchored receptors and only then pore formation is induced. Mechanisms of resistance in target pests were found to be often associated with mutations affecting the binding to these cadherin receptors. Hence, a proposed solution to overcome such cadherin-based resistance was "the rational design of improved toxins" (Sóberon et al., 2007, 2009). This led to the development of modified Cry1 toxins, so called CryMod toxins, lacking an alpha-helix that circumvented the cadherin-binding step by oligomerizing simply in the presence of trypsin and, subsequently, continue to induce pore formation requiring only binding to "secondary" receptors (Sóberon et al., 2007). Vachon et al. (2012) challenge the validity of this model and also Pigott and Ellar (2007) pointed out that "other explanations of the data are possible." The credibility of the sequential binding model was further eroded because of later, admitted manipulations of images of the gels, including the removal of stains from the blot and shifting positions of the bands of the blot (e.g., Jimenez-Juarez et al., 2013), which were offered as evidence for the sequential binding model in a total of 11 publications. We conclude that the sequential binding model is, therefore, in need of independent validation and experimental reconciliation with the critique by Vachon et al. (2012) and Pigott and Ellar (2007).

Yet another model has been suggested by Zhang et al. (2005, 2006a) that differs from the two above in that pore formation is not an essential feature anymore in the cause of death of the insect. Instead the signal transduction model proposes that binding of Cry toxin monomers to cadherin activates an intracellular cell death mechanism (Smouse and Nishiura, 1997; Zhang et al., 2005, 2006a). This model also has been questioned by Vachon et al. (2012) and also by Soberón et al. (2009) who developed the competing "sequential binding model." In contrast, Jurat-Fuentes et al. (Jurat-Fuentes and Adang, 2006), suggested a combination of the Zhang et al. $(2005,2006 a)$ and the "sequential binding" model to be at work, and Kumar and Kumari (2015) consider both modes of action to act in a complementary fashion. Most authors, however, seem to agree that much still needs to be learned about the modes of action of Cry proteins. Pigott and Ellar (2007) expect that "as more toxin receptors are discovered and as our understanding of toxin-receptor interactions increases, it will be interesting to see the extent to which Cry toxins utilize a common mode of action."
Further complexity has been added to the presented new proposals of modes of action of Cry toxins by research suggesting that Cry toxins require the interaction with gut microbes in order to exert their lethal effects in target pest organisms (Broderick et al., 2006, 2009). When highly susceptible lepidopteran larvae were fed with antibiotics prior to being offered Cry toxin-spiked diet, the Cry toxins lost entirely their activity and no adverse effects on survival could be observed. The hypothesis proposed is that the Cry toxin induced pore formation of the midgut of susceptible larvae allows pathogenic gut bacteria to enter the hemocoel, allowing the bacteria to multiply and kill the host larvae via septicemia. Without the presence of such bacteria Cry toxins alone do not kill the larva (Broderick et al., 2006, 2009). When Enterococcus faecalis bacteria were added again to the diet, susceptibility to the Cry toxins was restored and high mortality observed. Hence, E. faecalis, which is a commensal bacteria in an intact gut, can become a pathogen when invading the hemocoel. A process the authors referred to as the "commensalto-pathogen" switch (Mason et al., 2011). Similarly, Jung and Kim (2006) reported that while B. thuringiensis subsp. aizawai (Bta) did efficiently kill third instar Spodoptera exigua larvae, it did not cause high mortality of fifth instar larvae. But when adding nematodes to Bt fed fifth instar larvae, it resulted in significant synergistic effects. They also suggested that this was due to Bta damaging at least somewhat the midgut cells of the fifth instars allowing the nematodes to enter the hemocoel. While the controversy remains regarding whether or not midgut microbiota (bacteria or nematodes) is essential for Cry toxins to kill susceptible insect larvae (Johnston and Crickmore, 2009; Raymond et al., 2009), it does highlight that the modes of action of Cry toxins are far from conclusive to date (Graf, 2011), and that co-factors which naturally occur in the environment impact the efficacy and specificity of Cry toxins which may help explaining some of the effects of Cry toxins on non-target organismes reported in the literature.

\section{SIGNIFICANT EFFECTS OF SINGLE CRY TOXINS ON NON-TARGET ORGANISMS}

Interestingly, there are indeed many documented cases of crossorder activities of Cry toxins on non-target organisms including reports about a range of lethal and non-lethal developmental (e.g., Lövei and Arpaia, 2005; Hilbeck and Schmidt, 2006; Marvier et al., 2007; Lövei et al., 2009; van Frankenhuyzen, 2009, 2013) or behavioral effects (e.g., Meier and Hilbeck, 2001; Zemkova Rovenska et al., 2005) challenging the narrow specificity narrative of Cry toxins, in particular when expressed as activated Cry toxins in the GM plants (Table 2). These reports include significant adverse effects of Cry toxins on nontarget coccinellid species, Harmonia axyridis and Henosepilachna vigintioctomaculata (Stephens et al., 2012; Song et al., 2012) with research groups reporting significant cross-order effects of lepidopteran active Cryl proteins on coleopteran coccinellid predators both when administered directly (Dhillon and Sharma, 2009; Schmidt et al., 2009; Hilbeck et al., 2012a) and via unaffected and affected prey (Zhang et al., 2006a,b,c; Table 2). In some cases reports of adverse effects even on non-arthropod 
species have been published. When studying Cry toxins expressed in GM maize material with the snail species Cantareus aspersus, the researchers found 25\% lower growth rate than in the control treatment (Kramarz et al., 2009). Just recently Shu et al. (2015) reported about significant effects of Cry1Ab from Mon810 maize on compost worm Eisenia fetida. Furthermore, several researchers reported about adverse effects of Cry toxins from GM host plant material on several aquatic organisms. In laboratory feeding trials, Rosi-Marshall et al. (2007) and Chambers et al. (2010) showed that consumption of single Cry toxin maize plant material reduced growth and increased mortality of the nontarget stream insects Lepidostoma liba and Helicopsyche borealis, respectively. Also Bøhn et al. (2008; Bøhn et al., 2010) reported that mortality was higher, a lower proportion of females reached sexual maturation, and the overall egg production was lower in Daphnia magna that were fed CrylAb toxin producing GM maize compared to D. magna fed control maize. The authors argued specifically that the combination of reduced fitness with earlier onset of reproduction of $D$. magna fed Cry toxin maize indicated a direct toxic effect. Other aquatic taxa for which negative effects on single species have been observed include crane flies (Isopods; 19\% growth reduction; Jensen et al., 2010), Chironomids (Prihoda and Coats, 2008), and even crayfish (Linn and Moore, 2014).

The reported diversity of lethal and sublethal, chronic effects may sum up and lead to shifts in species composition at the community level. For example, Campos and Hernandez (2015) reported significant differences in dung beetle species composition-an important functional group-possibly leading to impaired ecosystems services such as feces removal, seed dispersal, edaphic aeration, and incorporation of organic matter. For aquatic habitats, Axelsson et al. (2011) reported that the composition of aquatic insect communities colonizing the litter from Cry3Aa expressing GM trees was significantly affected in unanticipated ways. Similarly, Rosi-Marshall et al. (2007) raised concerns that effects of Bt pollen and debris may negatively affect caddisflies and the food-web. Although this seems not to be the case for highly degraded industrial agricultural habitats (Chambers et al., 2010), the risk could not be clarified for more natural terrestrial and aquatic habitats which play an important role in ecosystem functioning.

In light of the above reports, it is clear that the claim of no reported adverse effects of single Cry toxins on cross-order nontarget organisms is not supported by the scientific evidence in the scientific literature. In fact, there is an increasing body of evidence suggesting significant effects of Cry toxins far beyond the originally postulated primary taxa of herbivorous target pest organism are possible.

\section{COMBINATORIAL EFFECTS OF CRY PROTEINS}

Combinatorial (including synergistic) effects of Bt toxins were reported already decades ago (e.g., Wu et al., 1985). Best known are the synergistic effects of spores of $B$. thuringiensis subsp. kurstaki to increase toxicity of Cry toxins in susceptible and resistant larvae of the diamondblack moth, Plutella xylostella (Dubois and Dean, 1995; Tang et al., 1996; Liu et al., 1998). Cry toxins combined with spores "can be toxic even though the toxins and spores have little or no independent toxicity" (Liu et al., 1998). Tang et al. (1996) observed synergistic effects among spores and the three Cry toxins CrylAa, CrylAb, and CrylAc. They also reported about synergistic effects between spores and Cry1C toxins on P. xylostella but, interestingly, not between spores and Cry2A toxin. However, since spores play no role in stacked or pyramided Bt crops-although they may still be around naturally_combinatorial effects of Cry toxins with other compounds encountered in nature are at the center of this review. These include combinatorial effects with (a) other Cry toxins, (b) bacteria-derived compounds, (c) plant-derived compounds and (d) insect-derived compounds. In the following, we address the reported effects (phenomena) and the suggested modes of actions (mechanisms) separately. In Table 2, we compiled the data from some widely cited key reports to allow for a quick overview of reported combinatorial effects, the involved compounds, test organisms, and proposed mechanisms.

\section{Combinatorial Effects}

\section{Combinatorial Effects of Different Cry Toxins}

Of the eight studies listed in Table 2 that tested various Cry toxin combinations, seven reported significant combinatorial effects involving lepidopteran and dipteran species. Lee et al. (1996) reported a synergistic effect for a combination of CrylAa with CrylAc but an antagonistic effect for Cry1 Aa and Cry1 Ab and no combinatorial effect for Cry1 Ab and Cry1 Ac in Lymantria dispar. Interestingly, when keeping Cry1Aa stable (at 1) but increasing Cry1Ac two-fold (1:2), susceptibility increased from 49.9 to 34.9 ng ID (growth inhibition dose). But when increasing Cry1Ac more (1:4, 1:6 up to $1: 12$ ), susceptibility dropped substantially. Yet, none of these combinatorial effects was observed in Bombyx mori, the other test organism (Lee et al., 1996). More recently, Sharma et al. (2010) reported synergistic effects of various Cry1A toxins in Chilo partellus larvae. Poncet et al. (1995) found synergistic and additive effects of combined Cry toxins in three different mosquito species. Both Ibargutxi et al. (2008) and Yunus et al. (2011) reported synergistic effects of Cry1Ac and Cry2A toxins on Earias insulana, the spotted bollworm. In contrast, in two studies involving Helicoverpa armigera larvae and testing a similar combination of Cry1Ac and Cry1F, Ibargutxi et al. (2008) found no synergistic interaction while Charkrabarti et al. (1998) did (Table 2).

\section{Combinatorial Effects of Cry Toxins with Bacteria-derived Compounds [Cytolytic (Cyt) Toxins]} Rincon-Castro et al. (1999) tested CrylAc toxins and Cyt1A1 toxins from engineered bacteria on Trichoplusia ni cell lines and larvae and found antagonistic effects. In contrast, Cyt1A proteins were found to synergize toxicity of Cry $4 \mathrm{~A}$ and Cry $4 \mathrm{~B}$ toxins, Cry10Aa and Cry11Aa in mosquito larvae (Chang et al., 1993; Wu et al., 1994; Wirth et al., 2004; Fernández-Luna et al., 2010). In fact, Wirth et al. (2004) reported that when Cry toxins from Bti were combined with B. sphaericus, in the presence or absence of Cyt1Aa, synergistically increased 
toxicity and an expanded host range were observed. Also Promdonkoy et al. (2005) reported that Cry4Ba toxins were toxic to $A$. aegypti larvae but virtually inactive to C. quinquefasciatus larvae. Cyt2Aa2 exhibited moderate activity against $A$. aegypti and $C$. quinquefasciatus larvae. But the combination of both toxins dramatically increased toxicity to both $A$. aegypti and C. quinquefasciatus larvae. Chitinases produced by bacterial $B$. thuringiensis increased activity of the produced Cry toxins more than two-fold in Spodoptera exigua larvae (Liu et al., 2002, Table 2). Chitinases are widely produced in many bacterial $B$. thuringiensis strains and in some cases enhanced the toxicity of the produced Cry toxins (Ramírez-Suero et al., 2011; Hu et al., 2013). It was proposed that they could be used to enhance efficacy of Bt toxins for pest control (Liu et al., 2002).

\section{Combinatorial Effects of Cry Toxins with Insect-derived Compounds}

Chen et al. (2007) reported that a peptide fragment of a toxin-binding cadherin isolated from Manduca sexta guts and expressed in E. coli synergistically enhanced toxicity of Cry1 toxins in other lepidoptera species (Table 2; Chen et al., 2007). Similarly, a fragment of a cadherin from A. gambiae was found to enhance the toxicity of Cry $4 \mathrm{Ba}$ mosquitocidal toxins. For both types of co-factors, effects of individual proteins were often lower and non-lethal while in combination observed effects were stronger and lethal.

\section{Combinatorial Effects of Cry Toxins with Plant-derived Compounds}

Mohan et al. (2008) report synergistic effects of Cry2A toxin with plant defense compounds like Mir1-cysteine protease (Table 2) in maize varieties from Antiqua (Carribean). The combinatorial effects observed were lethal and, as in the example above, much stronger than the sub-lethal effects caused by Mir-CP alone. They were discovered in exotic maize varieties from Antiqua (Carribean) and bred conventionally into local varieties. Also here, effects of individual proteins were at best sublethal but when administered in combination effects were more dramatic and lethal (Table 2).

\section{Proposed Mechanisms for Combinatorial Effects}

Below, we summarize the diversity of possible mechanisms proposed for the various observed combinatorial effects as this information will contribute to understanding whether combinatorial effects can be predicted.

\section{Combinatorial Effects of Different Cry Toxins}

Three different hypotheses are proposed. One hypothesis suggests that individual pores are formed by each CrylA toxin individually and may act cooperatively, together inducing higher toxicity. A second theory proposes the formation of additional hetero-oligomers which may have better insertion ability than a homo-oligomer complex (Charkrabarti et al., 1998). A third theory suggests that the toxin mix might enhance toxicity by preventing non-productive binding (Schnepf et al., 1998). However, all of these hypotheses presume that all toxin molecules interact similarly with the BBMVs following more or less the "classical model." Sharma et al. (2010) found that all three Cry toxin combinations showed increase in binding and direct positive correlation between increased binding and mortality. Many reports involve a great deal of speculation.

\section{Combinatorial Effects of Cry Toxins with Cytolytic (Cyt) Toxins}

As possible mechanism of the observed antagonistic effect between a Cry1 toxin and the cytolitic Cyt1A1, the forming of a complex blocking one or more binding sites or the competition for space instead of receptors was offered as explanation. However, none of this has been confirmed yet. For the observed synergistic effects between Cry11Aa and Cyt toxin, Pérez et al. (2005) suggest that the Cyt1Aa toxin acts as receptor for Cry11Aa. Wirth et al. (2004) propose an interplay between different affinities of the varying toxins for receptor binding sites as mechanism-either masking or enhancing toxicity through competition, blocking or preferential binding dynamics working in conjunction.

\section{Combinatorial Effects of Cry Toxins with Insect-derived Compounds}

For combinatorial effects with insect-derived compounds like various cadherin fragments or chitinolytic proteases different mechanisms have been suggested supported by data to some degree. Some researchers suggested that the presence of cadherin binding sites, i.e., fragments of cadherin receptors isolated from different target pest organisms allowed for increased oligomerization of activated, monomeric Cry toxins which in turn increased the ability of a Cry toxin-CR complex to insert into the midgut membrane and induce pore formation (Chen et al., 2007; Park et al., 2009). Chitinolytic proteases are known to affect the peritrophic matrix (PM) and, thus, like cysteine proteases, allow greater access for Cry toxins to epithelial cells where pore formation takes place. The PM is an extracellular matrix of chitin, glycoproteins and proteoglycans that lines and protects the midgut epithelium from damage and assists in nutrient uptake. Through greater (affinity) or faster access, their efficacy is likely enhanced and toxicity increased, meaning a smaller dose of Cry toxins can induce the formation of more pores quickly.

\section{Combinatorial Effects of Cry Toxins with Plant-derived Compounds}

For combinatorial effects with plant-derived compounds like the Mir-cysteine proteases (Mir-CP), it was suggested that they increase the permeability of the PM which in turn facilitates the movement of Cry toxins through the PM to allow greater access to epithelial cells where pore formation takes place.

\section{DISCUSSION}

The objective of this review was to evaluate the scientific basis of the claims serving as the rationale for minimizing or omitting the testing of combinatorial effects of multiple Cry toxins expressed in stacked GM crop plants. To do so we compiled and evaluated published experimental evidence. 


\section{Narrow Specificity Narrative Depends on Definition of Efficacy and Reference Systems}

In our analysis, we observed that the prevailing narrative of specificity is based on a narrow economically motivated definition of efficacy. This definition of efficacy relies on the "quick kill" from experiments carried out with a narrow spectrum of focal-because economically important-pest species. In the context of ecological risk assessment, such a narrow definition is insufficient and non-precautionary. When extending the definition of efficacy beyond a "quick kill," thus, including ecologically relevant endpoints like sublethal effects that include developmental time and growth, or cumulative lethal effects over the entire juvenile life stage ("slow kill") or reproductive effects, we see little evidence to support the assumption of narrow specificity.

However, a current report commissioned by COGEM (de Schrijver et al., 2014) and van Frankenhuyzen (2013) use mortality under the "quick kill" definition as the sole meaningful indicator for specificity. From an ecotoxicological and agronomic pest control perspective, this may suffice in particular when the focus lays on short-lived B. thuringiensis based pesticides. However, it does not suffice from an ecological, longterm perspective resulting from year round large-scale industrial cultivation of Bt crops including soybeans, maize, and cotton. The latter produce and release Bt toxins at an unprecedented spatio-temporal magnitude in agroecosystems. We argue that this can and probably has already lead to shifts in community structures and alterations in ecosystem services that may become particularly noticable outside of highly disturbed industrial agricultural areas (Axelsson et al., 2011; Campos and Hernandez, 2015). Agroecosystems in industrial agricultural areas are highly degraded and subject to multiple, persistent anthropogenic stressors, like chemical fertilizer, and massive pesticide inputs (Benbrook, 2012; Douglas and Tooker, 2015). Thus, all invertebrate communities in such industrial agroecosystems-terrestrial and aquatic-are the survivors of these degraded conditions, and, therefore, the impact of a single stressor, such as Bt toxins, may not be readily discernable (Chambers et al., 2010). Massive areal applications of pesticides in addition to the ubiquitous routine treatment of seeds of industrial commodity crops with persistent neonicotinoids will likely mask any additional effect of the bacterial Cry toxins (Douglas and Tooker, 2015). But with Cry toxin coding transgenes and GM plants moving beyond the arable field and entering also aquatic ecosystems, longterm ecosystem services, and conservation issues should receive special attention.

\section{Increasing Uncertainty on Modes of (Inter-)action of Cry Toxins}

Over the past decade, substantially differing modes of action have been proposed, which all are contested to some degree. The classical model of mode of action has largely been studied with crystalline $B$. thuringiensis produced proteins which require a complex solubilization and activation process. These steps of activating the crystalline $B$. thuringiensis proteins have been shortcut in GM plants most of which express the already activated Cry toxins. Much of the complex proposed modes of action that determine their "specificity" has been eliminated in GM plants. Neither particular $\mathrm{pH}$ conditions nor cleavage enzymes are required for their activation. Hence, with Cry toxin producing GM plants, specificity would be determinded exclusively by receptor binding and pore formation. However, with the signaling pathway model, pore formation may be obsolete and most of the proposed receptors are not necessarily restricted to target organisms or target taxa (e.g., Watanabe et al., 1995; Luan and Xu, 2007; Hulpiau and van Roy, 2009) as are trypsin and other suggested enzymes necessary for Cry toxin activation. Because research has focused on herbivorous target pest species, hardly any knowledge about the presence or absence of midgut receptors required for Cry toxin activation in insects outside of the studied range of herbivorous pests exists.

Furthermore, most of the research into the modes of action of the past decade was driven by exploring the mechanism underlying the spreading resistance in some target pests in order to find ways to overcome resistance (e.g., Soberon et al., 2012; Storer et al., 2012). Consequently, an even more narrow subset of target pests namely those that have evolved resistance was studied. Notably, none of the newly discovered modes of action were discussed or investigated in the context of non-target organisms. Except for two studies (Rodrigo-Simón et al., 2006; Song et al., 2012), no efforts have been spent on understanding the mechanisms behind the reported adverse effects on nontarget organisms despite the ensuing scientific dispute (Waltz, 2009a,b; Hilbeck et al., 2012b). In these disputes, the specifitiy of Bt-toxins are stressed in a paramount way. However, the narrow specificity narrative must be re-defined as more and more data on the cross-order acticivity are available (van Frankenhuyzen, 2009, 2013).

\section{No Lack of Reported Cross-order Effects of Single Cry Toxins}

From our analyses, we conclude that the claim of no reports of adverse effects of Cry toxins-directly or indirectly-on nontarget organisms is invalid. In the scientific literature both can be found, reports from experimental studies that do find adverse effects of Cry toxins and those that do not and the outcome is very sensitive to the applied methodology including exposure schemes and measured endpoints and the author's interpretation of the data. As the range of organisms and the endpoints tested have been expanding, scientists began to find adverse effects of Cry toxins administered directly as microbially- or plant-produced compounds or indirectly via prey on a far broader range of organisms than previously assumed (van Frankenhuyzen, 2009, 2013; de Schrijver et al., 2014).

Because regulatory standards for GMO-testing are lackingnot only in the EU-the scientific interpretation of effect studies are subject of intense debate in the science and regulatory community. Studies pointing at potential negative effects are met by heavy criticism from developers and proponents of GM products (e.g., Waltz, 2009a,b). Dissenting interpretations and extrapolations are typically based on different conceptual approaches to (narrow vs. broad) risk assessment (e.g., 
Andow et al., 2006; Hilbeck et al., 2011, 2012b; Wickson et al., 2013 vs. Romeis et al., 2006) or are primarily concerned with, and triggered by, the policy responses the reported adverse effects on non-target organisms invoked (e.g., Ricroch et al., 2010; Kuntz et al., 2013; Romeis et al., 2013) rather than driven by scientific curiosity.

Different outcomes of experiments determining the sensitivity of testing organisms have been linked to differences in exposure length and intensity via the offered diets during the time period tested. While in many studies reporting significant effects, the tested non-target organisms were exposed to the test substance (Cry toxin containing diets or prey) continuously throughout most or all of their (susceptible) larval stage, this is often not the case in the studies not finding significant effects. For example, Hilbeck et al. (1998a,b, 1999, 2012b) Schmidt et al. (2009), Dutton et al. (2002), Stephens et al. (2012), Zhang et al. (2006a,b), Dhillon and Sharma (2009) did ensure exposure throughout the (almost) entire larval stage and, consequently, did observe effects. This was not the case in studies by Romeis et al. (2004), Rodrigo-Simón et al. (2006), Porcar et al. (2010), Zhang et al. (2006c,d). In other cases, exposure was ensured throughout the entire larval stage but with intermittent phases of recovery by offering optimal, nonCry toxin diets (Alvarez-Alfageme et al., 2011) or by offering a Bt-laced suboptimal food in combination with a non-Bt optimal food (Zhang et al., 2014). The conclusions of Lövei et al. (2009) still hold today based on their meta-analysis: "it is clear that conclusions that Bt... transgene products have "no harm" to natural enemies are currently overgeneralized and premature."

\section{Combinatorial Cry Toxin Effects Commonly Known}

Also combinatorial effects of Cry toxins with other proteins or chemicals are actually widely recognized and reported in the literature. Combinatorial interactions of Cry toxins with each other or with other compounds enhancing their toxicity have been known and discussed in the scientific community since at least the 1980s (Wu et al., 1985; Schnepf et al., 1998). Already Schnepf et al. (1998) devoted a separate subchapter of this standard textbook on Bt toxins to unpredictable combinatorial interactions, mostly synergistic. They also pointed out the fact that "little is known about the mechanism of this synergistic interaction or potentiating effects," keeping in mind that this knowledge is restricted to the target pests studied. Again, combinatorial effects have been recognized and discussed only under a utilitarian "quick kill" narrative, i.e., in the context of enhancing the pest control capacity either of GM crop plants expressing the Cry toxins or of sprayable Cry toxin formulations. Under this utilitarian narrative, combinatorial effects are explored also as a means to aid its application in pest control strategies. For example, Li and Yu (2012) are heading a section on combinatorial effects in their chapter with "Utilizing the synergistic effect of helper proteins." Such "helper proteins" are in fact nothing else but substances that exert combinatorial effects with Bt toxins. For example, "chitinases for enhancing the entomotoxicity of engineered Bt strains" are receiving considerable attention to develop "new strategies" for pest control (see $\mathrm{Li}$ and $\mathrm{Yu}, 2012$ for references therein). Or as George and Crickmore (2012) put it "to boost the efficacy of $B t$ insecticidal toxins and overcome resistance posed by insect pests, the use of other proteins like cadherin fragments have been shown to be a successful strategy" or "also combinations of Cry toxins have proven to be a very useful strategy employed in boosting efficacy and hting resistance." For example, the secondary compound gossypol derived from the cotton has been applied in combination with CrylAc to boost its efficacy against a resistant population of Helicoverpa zea (Anilkumar et al., 2009). Why such previously unexpected and unpredictable combinatorial effects with co-factors-whether called "helpers" or otherwise-should be restricted only to those organisms that humans declare as target "pests" lacks a scientific hypothesis and certainly critical rigor (Then, 2010).

\section{No Predictability of Combinatorial Effects}

Many of the reported synergistic interactions in target organisms were entirely unpredictable and occured when their individual components did not elicit a response at all or only a sublethal response when tested in isolation. Liu et al. (1998) reported that spores and crystal toxins can act synergistically when administered together even if "the toxins and spores have little or no independent toxicity." Mohan et al. (2008) observed that low doses of Mir1-cysteine protease (a plant defense compound) "synergized sublethal doses of Cry2A" toxin. Similarly, it was shown that CR12-MPED peptide enhanced insecticidal activity of low Cry1Ab toxin doses (Table 2; Chen et al., 2007). Low (sublethal) doses of Mir1-CP synergized greatly sublethal doses of Cry2A. Both compounds hardly affected the lepidopterans when administered individually. Similarly for mosquito larvae, Promdonkoy et al. (2005) reported virtually no observable effect of a Cry $4 \mathrm{~B}$ toxin that in presence of a Cyt protein became deadly toxic to the larvae.

In some cases, cadherin receptor fragments increased toxicity of some Cry toxins but not of others (Lee et al., 1996). Masking effects by differential affinities to binding sites depending on kinetics of hetero-oligomer complex to receptors with higher or lower binding affinity or straightforward competing effects for binding sites were offered as explanation (Lee et al., 1996).

Chen et al. (2007) were surprised to find an enhancement of CrylAb toxicity. Because Cr12MPED peptide contains the critical Cry $1 \mathrm{Ab}$ binding region, it was expected that Cry1 $\mathrm{Ab}$ toxicity would be reduced in the presence of CR12 MPED peptides as they would bind the Cry toxin prior to their binding to the receptors in the midgut epithelium. Thus, the CR MPED bound Cry toxin would not be able anymore to induce pore formation. However, the opposite was true, also for Cry1Ac. In spectroscopy examinations, the authors found that CR12 MPED was present in an unfolded state which exposed more amino acid residues to the surrounding environment. It was speculated that this could modify interactions with Cry $1 \mathrm{~A}$ toxins in the insect midgut and enhance toxicity. Also Park et al. (2009) suggested a similar mechanism as Chen et al. (2007) where Cry3 toxins are activated to a $55 \mathrm{kDa}$ toxic fragment. This activated Cry3 toxic fragment binds to brush border membrane vesicles (BBMV) and recognizes a $144 \mathrm{kDa}$ binding region in the BBMV. However, Cry3 toxins differ in capacity to oligomerize, solve and bind. 
The suggested mechanism is presumed to be like CR12 MPED for lepidoptera. CR12 fragements induce the formation of a pre-pore Cry $1 \mathrm{Ab}$ oligomer, a critical step in the intoxication of lepidopteran larvae, leading to an enhancement of Cryl Ab toxicity. A similar mechanism is expected also for Cry3 and CR8-10 fragments.

Additionally, adverse effects can arise from combining various biotic stressors. When studying the singular effect of microbially produced, activated Cry toxin Cry1 Ab or via Cryl Ab producing GM maize in snails (Helix aspera), Kramarz et al. (2007a) found no negative effect on $H$. aspersa during the observed life stages. However, when snails were infected with nematodes, the growth of the snails was significantly slower than when fed control maize (Kramarz et al., 2007b). The authors concluded that "long-term exposure is needed to reveal an effect of Bt maize."

None of the observed combinatorial effects could have been predicted from the effects induced by their individual compounds. In a number of studies, researchers found that the synergistic lethal effects could be triggered in the absence of any effect when the toxins were administered individually or when administered at non-toxic doses or at low doses eliciting only sublethal effects (Table 2).

\section{CONCLUSIONS FOR REGULATIONS AND ENVIRONMENTAL RISK ASSESSMENT}

The regulatory requirements for the risk assessment of Bt-crops in the EU include testing combinatorial effects of different novel proteins such as $\mathrm{Bt}$ toxins expressed in the GMO. In practice, however, tests for combinatorial effects are carried out without plant material and with minimal effort. The rationale behind the test regime relies on the narrative of a narrow specificity of Bt toxins, which, from the developers perspective, backs their argument that relevant interactions between different Cry toxins should not be expected if the organisms are not known to be affected by single microbial Cry toxins. As a result, information on combinatorial effects is at best based on one laboratory study with a target pest species using a minimal combination of microbial Cry toxins.

\section{Need to Re-define the Specificity of Bt Toxins for the Risk Assessment of GMO}

We have argued here that the "narrow specificity" narrative of Cry toxins is based on an agro-economical perspective of specificity. However, in an environmental regulatory context, ecologically motivated studies (e.g., butterflies: Losey et al., 1999, lacewings: Hilbeck et al., 1998a, ladybird-beetles: Schmidt et al., 2009, daphnia: Bøhn et al., 2008, 2010; caddisflies Rosi-Marshall et al., 2007) are quite relevant as these must address protection goals and end-points that are different from and transcend those relevant from a narrow economically motivated pest-control perspective. Because of their relevance for environmental risk assessments in the European regulatory context, studies showing negative effects on groups of organisms which were not supposed to be sensitive to the Bt toxins in question and often occur outside of the agricultural field, were met with fierce criticism from circles favoring a narrow apporach to environmental risk assessment because they were pointing to existing uncertainties in these risk assessments and were not in line with the assumption of narrow specificity of Bt proteins. However, as these studies did deal with relevant questions for environmental risk assessments with a broader perspective, they were included in the evidence basis for policy decisions under the precautionary principle (e.g., German suspension for the cultivation of MON810, 2009; http://www.bvl.bund.de/ SharedDocs/Downloads/08_PresseInfothek/mon_810_bescheid. pdf?_blob=publicationFile\&v=2). As the available data show and the currently proposed modes of action of Bt-proteins are seemingly not exhaustive, the present definition of narrow specificity is of limited and, indeed, declining value for GMO environmental risk assessment in particular when operating under the precautionary principle.

\section{Mode of Action not Conclusive for the Assessment of Non-target Effects}

While not all non-target organisms will be adversely affected by Cry toxins, there is presently no way of predicting which species may or may not be affected based on the current state of understanding of the proposed modes of action of Cry toxins. The current knowledge on the modes of action for Bt toxins is clearly incomplete. All of the discussed requirements for activity of Cry toxins, suggested receptors or involved enzymes, occur in many organisms. Hence, more research into relating observed effects to possible mechanisms in non-target organisms going beyond the traditional narrow spectrum is urgently needed to better understand the likelihood and magnitude of non-target effects.

\section{Sublethal and Chronic Effects Bound to be Overlooked}

From our analyses, we conclude that relying on the narrow economic "quick kill" definition of efficacy, the risk assessment is bound to overlook sublethal, chronic, and cumulative adverse effects. Compared to acute lethal effects such effects are equally important for ecological functioning as they can trigger significant adverse effects on ecological processes. Sublethal effects in form of developmental delays or behavioral changes in host or prey preferences, for example, can lead to significant ecological consequences via disruption and altering of existing predator-prey relationships or synchronies within food webs. In an agroecosystem, such disruptions or shifts in preferences and behavior can cause significant shifts in arthropod community structures possibly favoring non-target pest species and giving rise to secondary pests (e.g., Lumbierres et al., 2004; Lu et al., 2010; Qui, 2010; Cantarino et al., 2015). Just recently, Campos and Hernandez (2015) observed adverse impacts of transgenic Cry toxin producing GM maize in Brazilian fields on the functional group dynamics within dung beetle communities. Furthermore, sublethal effects may substantiate only after several generations. For this reason, generational tests that provide the possibility to analyse important life-history parameters may improve the assessment of long-term effects on ecosystems. 
However, generational tests with GMOs (Bøhn et al., 2010; Shu et al., 2015) are virtually absent to date.

\section{Improvement of Regulatory Practice}

To date, information on non-target effects of GMOs do not have to comply with a standardized and agreed methodology in terms of test protocols or test batteries. Likewise, no standards for the testing of combinatorial effects of Cry toxins or possible interactions with other bioactive plant compounds exist (Dolezel et al., 2011). Currently, regulatory dossiers in the EU include only a minimal data set on combinatorial Cry toxin effects, justified on the grounds discussed above. However, the regulatory importance of combinatorial $\mathrm{Bt}$ effects has recently been recognized by the European Food Safety Authority (EFSA) and national biosafety authorities. For example, The Netherlands Commission on Genetic Modification (COGEM) recently commissioned two reports, one on the mode of action (van der Hoeven, 2014) and the other on the predictability of combinatorial Bt effects (de Schrijver et al., 2014). The reports were complemented by a scientific workshop of EFSA and COGEM in October 2014. While the reports list many of the key literature of this review, the conclusions of the authors clearly reflect the utilitarian perspective of pest and resistance management at the expense of detecting and managing risks on biodiversity and ecosystem services. While, de Schrijver et al. (2014) acknowledge certain types of combinatorial effects (addition, synergism, antagonism) that may exhibit a high level of species-specificity and cannot be predicted they also argue that sufficient information is available to conclude that Cry toxins with different primary order of activity are not likely to interact.

In contrast to this interpretation, we argue that the concept of primary-order specificity of Cry toxins should be discarded as more and more evidence is being published that Cry toxins are cross-order active in quite unexpected ways (van Frankenhuyzen, 2009, 2013). Hence, even on grounds of the assumption that combinatorial effects can only arise if single toxins elicit effects on their own in isolation, combinatorial effects in a number of nontarget insects should be expected. Together with the uncertainties regarding a multitude of possible modes of action of Cry toxins, the precautionary principle clearly applies. The first rational measure of precaution would be to require robust experimental testing of combinatorial effects of all Cry toxins as expressed in the stacked GM events on a broader taxonomic range of nontarget organisms selected independent of their pest status. Such experiments require ecologically relevant and agreed protocols which are indeed available since many years (Birch et al., 2004; Andow et al., 2008; Hilbeck et al., 2012b).

For both the scientific community and regulators another political issue urgently needs to be resolved. Any experiments with GMOs and non-target organisms are in need of GMO plant material and/or synthetic variants of the Bt toxins. At present, technology agreements linked with the purchase of seeds prevent the use of GM seeds in the regulatory pipeline for biosafety research and, thus, are limiting industry-independent research on the activity spectrum, the mode of action and on the combinatorial effects of multiple Bt traits. To resolve this problem, policy action is required to allow independent biosafety research not to be restricted to GMOs that are already commercially available.

\section{Inherent Biases and Gaps of Knowledge Unaccounted for in Current Regulatory Risk Assessments of GM Crops}

The recent report commissioned by the Netherlands Commission on Genetic Modification (COGEM; de Schrijver et al., 2014) did include some-but not all-of the studies listed in Table 2. Both van Frankenhuyzen (2013) and the updated version in the COGEM report (de Schrijver et al., 2014) recognized that the published data depart from the dominant narrative of narrow specificity and lack of reported effects of single Cry toxins on non-target beneficial organisms. Yet, in their interpretation, most studies reporting non-target effects were dismissed on the following grounds: their evidence was (i) "not established unequivocally" in comparison to other studies, (ii) "not confirmed" by "subsequent studies" or (iii) "at odds with other studies showing no effects" (de Schrijver et al., 2014, p. 36; van Frankenhuyzen, 2013, pp. 80-81). van Frankenhuyzen (2013, p. 81) stated that since the contradictions in quantitative data could not be resolved they presented "enough uncertainty to indicate lack of evidence for unequivocal cross-toxicity" and, therefore, these cases were excluded in an effort to maintain the dominant narrative, reducing the number of reported crossactivities substantially from 27 proteins affecting 69 high ranking taxa to 19 proteins affecting 45 taxa. We argue that a balanced evaluation in light of the different narratives explained above, in particular when working under the precautionary principle, should include these peer-reviewed, independent reports and engage in a deeper analysis as to the underlying methodological commonalities and causes explaining the differences between the contradicting studies as we have attempted in this review.

Furthermore, another serious gap of knowledge exists regarding interaction effects with other chemical pollutants in particular the many chemicals that are integral components of the industrial agricultural system and of GM crops. The majority of GM crops are also resistant against herbicides. These are systemic chemicals that are taken up by plants and translocated into all tissues including pollen and seeds. This has lead to a substantial increase in chemical use as well as residual chemical loads in the harvested products (Aris and Leblanc, 2011; Benbrook, 2012; Then, 2013). Additionally, maize seeds, both GM and conventional varieties, are routinely coated with chemicals such as the neonicotinoid Clothianidin. Because of seed coating, Chlothianidin has recently been shown to be present in substantial concentrations $(8 \mu \mathrm{g} / \mathrm{ml})$ in guttation fluid (Reetz et al., 2011) and in maize pollen (Krupke et al., 2012). Both are preferred sources of food for a wide range of beneficial insects, honeybees, predators, butterflies, and many more.

Neonicotinoids are also systemic and therefore result in similar exposure pathways as herbicidal residues and Cry toxins in GM crops. Despite the fact that Cry toxins, synthetic pesticides such as glufosinate, glyphosate, $2,4 \mathrm{D}$, Dicamba, and neonicotinoids may all be jointly present in GM crops, none 
of the synthetic pesticides have been tested in combination with single or multiple Cry toxins. For "SmartStax ${ }^{\circledR}$," the biggest stacked GM crop plant currently commercially produced combines 6 Cry toxins. From developers data, we calculated the total Cry toxin values (Stillwell and Silvanovich, 2007; Phillips, 2008; Table 1) and found that the toxin load, depending on the specific plant tissue, varies from 90 to 250 and from 140 to $1500 \mu \mathrm{g} \mathrm{Bt}$ toxin/g fresh and dry weight respectively. The toxin load from SmartStax introduced into the environment has been estimated to total $4.2 \mathrm{~kg} \mathrm{Bt} / \mathrm{ha}$ (Benbrook, 2012). With such unprecedented concentrations of potent bioactive bacterial toxins, we see a high probability that this increase of active ingredients will adversely affect the communities of organisms associated with these agroecosystems, alone and in conjunction

\section{REFERENCES}

Alvarez-Alfageme, F., Bigler, F., and Romeis, J. (2011). Laboratory toxicity studies demonstrate no adverse effects of CrylAb and Cry3Bb1 to larvae of Adalia bipunctata (Coleoptera: Coccinellidae): the importance of study design. Transgenic Res. 20, 467-479. doi: 10.1007/s11248-010-9430-5

Andow, D. A., Hilbeck, A., and Van Tuat, N. (eds.). (2008). Environmental Risk Assessment of Genetically Modified Organisms, Volume 4: Challenges and Opportunities with Bt Cotton in Vietnam. Wallingford: CABI Publishing.

Andow, D. A., Lövei, G. L., and Arpaia, S. (2006). Ecological risk assessment for Bt crops. Nat. Biotechnol. 24, 749-751. doi: 10.1038/nbt0706-749

Anilkumar, K. J., Sivasupramaniam, S., Head, G., Orth, R., Van Santen, E., and Moar, W. J. (2009). Synergistic interactions between Cryl Ac and natural cotton defenses limit survival of Cry1Ac-resistant Helicoverpa zea (Lepidoptera: Noctuidae) on Bt Cotton. J. Chem. Ecol. 35, 785-795. doi: 10.1007/s10886-0099665-x

Aris, A., and Leblanc, S. (2011). Maternal and fetal exposure to pesticides associated to genetically modified foods in Eastern Townships of Quebec, Canada. Reprod. Toxicol. 31, 528-533. doi: 10.1016/j.reprotox.2011.02.004

Axelsson, P. E., Hjältén, J., LeRoy, C. J., Whitham, T. G., Julkunen-Tiitto, R., and Wennström, A. (2011). Leaf litter from insect-resistant transgenic trees causes changes in aquatic insect community composition. J. Appl. Ecol. 48, 1472-1479. doi: 10.1111/j.1365-2664.2011.02046.x

Behle, R. W., McGuire, M. R., and Shasha, B. S. (1997). Effects of sunlight and simulated rain on residual activity of Bacillus thuringiensis formulations. J. Econ. Entomol. 90, 1560-1566.

Benbrook, C. M. (2012). Impacts of genetically engineered crops on pesticide use in the U.S. - the first sixteen years. Environ. Sci. Eur. 24:24. doi: 10.1186/21904715-24-24

Birch, A. N. E., Wheatley, R., Anyango, B., Arpaia, S., Capalbo, D., Getu Degaga, E., et al. (eds.). (2004). Environmental Risk Assessment of Transgenic Organisms, Volume 1: A Case Study of Bt Maize in Kenya. Wallingford, CT: CABI Publishing.

Bøhn, T., Traavik, T., and Primicerio, R. (2010). Demographic responses of Daphnia magna fed transgenic Bt-maize. Ecotoxicology 19, 419-430. doi: 10.1007/s10646-009-0427-x

Bøhn, T., Hessen, D. O., and Traavik, T. (2008). Reduced fitness of Daphnia magna fed a Bt-transgenic maize variety. Arch. Environ. Contam. Toxicol. 55, 584-592. doi: 10.1007/s00244-008-9150-5

Broderick, N. A., Raffa, K. F., and Handelsman, J. (2006). Midgut bacteria required for Bacillus thuringiensis insecticidal activity. Proc. Natl. Acad. Sci. U.S.A. 103, 15196-15199. doi: 10.1073/pnas.0604865103

Broderick, N. A., Robinson, C. J., McMahon, M. D., Holt, J., Handelsman, J., and Raffa., K. F. (2009). Contributions of gut bacteria to Bacillus thuringiensisinduced mortality vary across a range of Lepidoptera. BMC Biol. 7:11. doi: 10.1186/1741-7007-7-11

Campos, R. C., and Hernandez, M. I. M. (2015). Changes in the dynamics of functional groups in communities of dung beetles in Atlantic forest fragments adjacent to transgenic maize crops. Ecol. Indic. 49, 216-227. doi: 10.1016/j.ecolind.2014.09.043 with the likewise significant loads of herbicide and neonicotinoid residues. While such stacked varieties offer benefits to farmers for agronomic problems, these benefits may come with serious health and environmental risks that we find prudent to be experimentally studied prior to field release and market approval.

\section{ACKNOWLEDGMENTS}

This study was partially supported financially by the Federal Agency for Nature Conservation, Bonn (Bundesamt für Naturschutz BfN), Germany. Research project on "Combinatorial effects of Bt proteins" ("Kombinatiorische Wirkungen zwischen Bt-Proteinen"). We thank the reviewers for their helpful comments.

Cantarino, G., Ceddia, R., Areal, F. J., and Park, J. (2015). The impact of secondary pests on Bacillus thuringiensis (Bt) crops. Plant Biotechnol. J. 13, 601-612. doi: 10.1111/pbi.12363

Chambers, C. P., Whiles, M. R., Rosi-Marshall, E. J., Tank, J. L., Royer, T. V., Griffiths, N. A., et al. (2010). Responses of stream macroinvertebrates to Bt maize leaf detritus. Ecol. Appl. 20, 1949-1960. doi: 10.1890/09-0598.1

Chang, C. H., Yu, Y. M., Dai, S. M., Law, S. K., and Gill, S. S. (1993). Highlevel cryIVD and cytA gene expression in Bacillus thuringiensis does not require the 20 -Kilodalton protein, and the coexpressed gene products are synergistic in their toxicity to mosquitoes. Appl. Environ. Microbiol. 59, 815-821.

Charkrabarti, S. K., Mandoakar, A. D., Kumar, P. A., and Sharma, R. P. (1998). Synergistic effect of Cry1Ac and Cry1F delta-endotoxins of Bacillus thuringiensis on cotton bollworm, Helicoverpa armigera. Curr. Sci. 75, 663-664.

Chen, J., Hua, G., Jurat-Fuentes, J. L., Abdullah, M. A., and Adang, M. J. (2007). Synergism of Bacillus thuringiensis toxins by a fragment of a toxin-binding cadherin. Proc. Natl. Acad. Sci. U.S.A. 104, 13901-13906. doi: 10.1073/pnas.0706011104

CropLife International (2015). Environmental Risk Assessment for Breeding Stack Products: Methods and Regulatory Implications. Available online at: https:// croplife.org/wp-content/uploads/2015/05/CLI-ERAPT-Position-DocumentERA-for-Stacked-Products_FINAL2.pdf

de Schrijver, A., de Clerq, P., Booij, K., de Maagd, R., and van Frankenhuyzen, K. (2014). Can Interactions Between Bt Proteins be Predicted and How Should Effects on Non-target Organisms of GM Crops with Multiple Bt Proteins be Assessed? Commissioned and published by COGEM (The Netherlands Commission on Genetic Modification).

Delécluse, A., Poncet, S., Klier, A., and Rapoport, G. (1993). Expression of cryIVA and $c r y I V B$ genes, independently or in combination, in a crystal-negative strain of Bacillus thuringiensis subsp. israelensis. Appl. Environ. Microbiol. 59, 3922-3927.

Dhillon, M. K., and Sharma, H. C. (2009). Effects of Bacillus thuringiensis $\mathrm{d}$-endotoxins Cry1 Ab and Cry1Ac on the coccinellid beetle, Cheilomenes sexmaculatus (Coleoptera, Coccinellidae) under direct and indirect exposure conditions. Biocontrol Sci. Technol. 19, 407-420. doi: $10.1080 / 09583150902783801$

Dolezel, M., Miklau, M., Hilbeck, A., Otto, M., Eckerstorfer, M., Heissenberger, A., et al. (2011). Scrutinizing the current practice of the environmental risk assessment of GM maize applications for cultivation in the EU. Environ. Sci. Eur. 23:33. doi: 10.1186/2190-4715-23-33

Douglas, M. R., and Tooker, J. F. (2015). Large-scale deployment of seed treatments has driven rapid increase in use of neonicotinoid insecticides and preemptive pest management in U.S. field crops. Environ. Sci. Technol. 49, 5088-5097. doi: $10.1021 /$ es506141g

Dubois, N. R., and Dean, D. H. (1995). Synergism between CryIA insecticidal crystalproteins and spores of Bacillus thuringiensis, other bacterial spores, and vegetative cells against Lymantria dispar (Lepidoptera: Lymantriidae) larvae. Entomol. Soc. Am. 24, 1741-1747.

Dutton, A., Klein, H., Romeis, J., and Bigler, F. (2002). Uptake of Bttoxin by herbivores feeding on transgenic maize and consequences for the 
predator Chrysoperla carnea. Ecol. Entomol. 27, 441-447. doi: 10.1046/j.13652311.2002.00436.x

EFSA (2010a). Guidance on the environmental risk assessment of genetically modified plants. EFSA J. 8:1879. doi: 10.2903/j.efsa.2010.1879

EFSA (2010b). Scientific opinion for the placing on the market of insect resistant and herbicide tolerant genetically modified maize MON 89034×1507 × NK603 and all sub-combinations of the individual events as present in its segregating progeny, for food and feed uses, import and processing under Regulation (EC) No 1829/2003 from Dow AgroSciences and Monsanto. EFSA J. 8:1782. doi: 10.2903/j.efsa.2010.1782

Fernandez-Cornejo, J., Seth, W., Mike, L., and Lorraine, M. (2014). Genetically Engineered Crops in the United States, ERR-162. U.S. Department of Agriculture, Economic Research Service.

Fernández-Luna, M. T., Tabashnik, B. E., Lanz-Mendoza, H., Bravo, A., Soberón, M., and Miranda-Ríos, J. (2010). Single concentration tests show synergism among Bacillus thuringiensis subsp. israelensis toxins against the malaria vector mosquito Anopheles albimanus. J. Invertebr. Pathol. 104, 231-233. doi: 10.1016/j.jip.2010.03.007

Garcia-Alonso, M., Jacobs, E., Raybould, A., Nickson, T., Sowig, P., Willekens, H., et al. (2006). A tiered system for assessing the risk of genetically modified plants to nontarget organisms. Environ. Biosafety Res. 5, 57-65. doi: 10.1051/ebr:2006018

George, Z., and Crickmore, N. (2012). "Bacillus thuringiensis applications in agriculture," in Bacillus thuringiensis Biotechnology, ed E. Sansinenea (Heidelberg: Springer Verlag), 19-40.

Graf, J. (2011). Shifting paradigm on Bacillus thuringiensis toxin and a natural model for Enterococcus faecalis septicemia. MBio 2:e0161-11. doi: 10.1128/mbio.00161-11

Haider, M. Z., and Ellar, D. J. (1987). Analysis of the molecular basis of insecticidal specificity of Bacillus thuringiensis crystal delta-endotoxin. Biochem J. 248, 197-201.

Hernández-Rodríguez, C. S., Hernández-Martínez, P., Van Rie, J., Escriche, B., Ferré, J. (2013). Shared midgut binding sites for CrylA.105, Cry1Aa, Cry1Ab, CrylAc and CrylFa proteins from Bacillus thuringiensis in two important corn pests, Ostrinia nubilalis and Spodoptera frugiperda. PLoS ONE 8:e68164. doi: 10.1371/journal.pone.0068164

Hilbeck, A. (2001). Implications of transgenic, insecticidal plants for insect and plant biodiversity. Perspect. Plant Ecol. Evol. Syst. 4, 43-61. doi: 10.1078/14338319-00014

Hilbeck, A. (2002). “Transgenic host plant resistance and non-target effects," in Genetically Engineered Organisms. Assessing Environmental and Human Health Effects, eds D. K. Letourneau and B. E Burrows (Washington, DC: CRC Press), $167-185$.

Hilbeck, A., and Schmidt, J. E. U. (2006). Another view on Bt-proteins-how specific are they and what else might they do. Biopesticides Int. 2, 1-50.

Hilbeck, A., Baumgartner, M., Fried, P. M., and Bigler, F. (1998a). Effects of transgenic Bacillus thuringiensis corn-fed prey on mortality and development time of immature Chrysoperla carnea (Neuroptera: Chrysopidae). Environ. Entomol. 27, 480-487. doi: 10.1093/ee/27.2.480

Hilbeck, A., McMillan, J. M., Meier, M., Humbel, A., Schlaepfer-Miller, J., and Trtikova, M. (2012a). A controversy re-visited: Is the coccinellid Adalia bipunctata adversely affected by Bt toxins? Environ. Sci. Eur. 24:10. doi: $10.1186 / 2190-4715-24-10$

Hilbeck, A., Meier, M., and Trtikova, M. (2012b). Underlying reasons of the controversy over adverse effects of Bt toxins on lady beetle and lacewing larvae. Environ. Sci. Eur. 24:9. doi: 10.1186/2190-4715-24-9

Hilbeck, A., Meier, M., Römbke, J., Jänsch, S., Teichmann, H., and Tappeser, B. (2011). Environmental risk assessment of genetically modified plants - concepts and controversies. Environ. Sci. Eur. 23, 1-16. doi: 10.1186/2190-4715-23-13

Hilbeck, A., Moar, W. J., Pusztai Carey, M., Filippini, A., and Bigler, F. (1998b). Toxicity of Bacillus thuringiensis CrylAb toxin to the predator Chrysoperla carnea (Neuroptera: Chrysopidae). Entomol. Soc. Am. 27, 1255-1263.

Hilbeck, A., Moar, W. J., Pusztai-Carey, M., Filippini, A., and Bigler, F. (1999). Prey mediated effects of Cry1Ab toxin and protoxin and Cry2A protoxin on the predator Chrysoperla carnea. Entomol. Exp. Appl. 91, 305-316. doi: 10.1046/j.1570-7458.1999.00497.x

Hoefte, H., and Whiteley, H. R. (1989). Insecticidal crystal proteins of Bacillus thuringiensis. Microbiol. Rev. 53, 242-255.
Hofmann, F., Otto, M., and Wosniok, W. (2014). Maize pollen deposition in relation to distance from the nearest pollen source under common cultivation - results of 10 years of monitoring (2001 to 2010). Environ. Sci. Eur. 26, 24. doi: 10.1186/s12302-014-0024-3

Hu, S., Zhang, X., Li, Y., Ding, X., Hu, X., Yang, Q., et al. (2013). Constructing Bacillus thuringiensis strain that co-expresses Cry2Aa and chitinase. Biotechnol. Lett. 35, 1045-1051. doi: 10.1007/s10529-013-1171-0

Hulpiau, P., and van Roy, F. (2009). Molecular evolution of the cadherin superfamily. Int. J. Biochem. Cell Biol. 41, 349-369. doi: 10.1016/j.biocel.2008.09.027

Ibargutxi, M. A., Muñoz, D., Ruíz de Escudero, I., and Caballero, P. (2008). Interactions between Cry1 Ac, Cry2 Ab, and Cry1Fa Bacillus thuringiensis toxins in the cotton pests Helicoverpa armigera (Hübner) and Earias insulana (Boisduval). Biol. Cont. 47, 89-96. doi: 10.1016/j.biocontrol.2008.07.003

Jensen, P. D., Dively, G. P., Swan, C. M., and Lamp, W. O. (2010). Exposure and nontarget effects of transgenic Bt corn debris in streams. Environ. Entomol. 39, 707-714. doi: 10.1603/EN09037

Jiménez-Juárez, N., Muñoz-Garay, C., Gómez, I., Saab-Rincon, G., DamianAlmazo, J. Y., Gill, S. S., et al. (2007). Bacillus thuringiensis Cry1Ab mutants affecting oligomer formation are non-toxic to Manduca sexta larvae. J. Biol. Chem. 282, 21222-21229. doi: 10.1074/jbc.M701314200

Jimenez-Juarez, N., Munoz-Garay, C., Gomez, I., Saab-Rincon, G., DamianAlmazo, J. Y., Gill, S. S., et al. (2013). Bacillus thuringiensis Cry1Ab mutants affecting oligomer formation are non-toxic to Manduca sexta larvae. Additions and Corrections. J. Biol. Chem. 288, 8560. doi: 10.1074/jbc.A113.701314

Johnston, P. R., and Crickmore, N. (2009). Gut bacteria are not required for the insecticidal activity of Bacillus thuringiensis toward the tobacco hornworm, Manduca sexta. Appl. Environ. Microbiol. 75, 5094-5099. doi: 10.1128/AEM.00966-09

Jung, S., and Kim, Y. (2006). Synergistic effect of Xenorhabdus nematophila K1 and Bacillus thuringiensis subsp. aizawai against Spodoptera exigua (Lepidoptera: Noctuidae). Biol. Control 39, 201-209. doi: 10.1016/j.biocontrol.2006.07.002

Jurat-Fuentes, J. L., and Adang, M. J. (2006). Cry toxin mode of action in susceptible and resistant Heliothis virescens larvae. J. Invertebr. Pathol. 92, 166-171. doi: 10.1016/j.jip.2006.01.010

Kramarz, P. E., De Vaufleury, A., and Carey, M. (2007a). Studying the effect of exposure of the snail Helix aspersa to the purified Bt toxin, CrylAb. Appl. Soil Ecol. 37, 169-172. doi: 10.1016/j.apsoil.2007.06.006

Kramarz, P. E., De Vaufleury, A., Gimbert, F., Cortet, J., Tabone, E., Neumann Andersen, M., et al. (2009). Effects of Bt-maize material on the life cycle of the land snail Cantareus aspersus. Appl. Soil Ecol. 42, 236-242. doi: 10.1016/j.apsoil.2009.04.007

Kramarz, P. E., de Vaufleury, A., Zygmunt, P. M. S., and Verdun, C. (2007b). Increased response to cadmium and Bacillus thuringiensis maize toxicity in the snail Helix aspersa infected by the nematode Phasmarhabditis hermaphrodita. Environ. Toxicol. Chem. 26, 73-79. doi: 10.1897/06-095R.1

Krupke, C. H., Hunt, G. J., Eitzer, B. D., Andino, D., and Given, K. (2012). Multiple routes of pesticide exposure for honey bees living near agricultural fields. PLoS ONE 7:e29268. doi: 10.1371/journal.pone.0029268

Kumar, S., and Kumari, R. (2015). Occurrence of molecularly diverse Bt Crytoxinresistant mutations in insect pests of $\mathrm{Bt}^{+}$corn and cotton crops and remedial approaches. Curr. Sci. 108, 1-8.

Kuntz, M., Davison, J., and Ricroch, A. E. (2013). What the French ban of Bt MON810 maize means for science-based risk assessment. Nat. Biotechnol. 31, 498-500. doi: 10.1038/nbt.2613

Lee, M. K., Curtiss, A., Alcantara, E., and Dean, D. H. (1996). Synergistic effect of the Bacillus thuringiensis toxins CryIAa and CryIAc on the gypsy moth, Lymantria dispar. Appl Envir Microbiol 62, 583-586.

Li, L., and Yu, Z. (2012). "Genetically modified Bacillus thuringiensis biopesticides," in Bacillus thuringiensis Biotechnology, ed E. Sansinenea (Springer Verlag), 231-258.

Linn, M. D., and Moore, P. A. (2014). The effects of Bt corn on rusty crayfish (Orconectes rusticus) growth and survival. Arch. Environ. Contam. Toxicol. 67, 36-443. doi: 10.1007/s00244-014-0061-3

Liu, M., Cai, Q. X., Liu, H. Z., Zhang, B. H., Yan, J. P., and Yuan, Z. M. (2002). Chitinolytic activities in Bacillus thuringiensis and their synergistic effects on larvicidal activity. J. Appl. Microbiol. 93, 374-379. doi: 10.1046/j.13652672.2002.01693.x 
Liu, Y. B., Tabashnik, B. E., Moar, W. J., and Smith, R. A. (1998). Synergism between Bacillus thuringiensis spores and toxins against resistant and susceptible diamondback moths (Plutella xylostella). Appl. Environ. Microbiol. 64, 1385-1389.

Losey, J. E., Rayor, L. S., and Carter, M. E. (1999). Transgenic pollen harms monarch larvae. Nature 399, 214. doi: 10.1038/20338

Lövei, G. L., and Arpaia, S. (2005). The impact of transgenic plants on natural enemies: a critical review of laboratory studies. Entomol. Exp. Appl. 114, 1-14. doi: 10.1111/j.0013-8703.2005.00235.x

Lövei, G. L., Andow, D. A., and Arpaia, S. (2009). Transgenic Insecticidal crops and natural enemies: a detailed review of laboratory studies. Environ. Entomol. 38, 293-306. doi: 10.1603/022.038.0201

Lu, Y., Wu, K., Jiang, Y., Xia, B., Li, P., Feng, H., et al. (2010). Mirid bug outbreaks in multiple crops correlated with wide-scale adoption of Bt cotton in China. Science 328, 1151-1154. doi: 10.1126/science.1187881

Luan, Y., and Xu, W. (2007). The structure and main functions of aminopeptidase, N. Curr. Med. Chem. 14, 639-647. doi: 10.2174/092986707780059571

Lumbierres, B., Albajes, R., and Pons, X. (2004). Transgenic Bt maize and Rhopalosiphum padi (Hom., Aphididae) performance. Ecol. Entomol. 29, 309-317. doi: 10.1111/j.0307-6946.2004.00597.x

Marvier, M., McCreedy, C., Regetz, J., and Kareiva, P. (2007). A meta-analysis of effects of Bt cotton and maize on non-target invertebrates. Science 316, 1475-1477. doi: 10.1126/science.1139208

Mason, K. L., Stepien, T. A., Blum, J. E., Holt, J. F., Labbe, N. H., Rush, J. S., et al. (2011). From commensal to pathogen: translocation of Enterococcus faecalis from the midgut to the hemocoel of Manduca sexta. MBio 2:e0065-11. doi: 10.1128/mBio.00065-11

Meier, M., and Hilbeck, A. (2001). Influence of transgenic Bacillus thuringiensis corn-fed prey on prey preference of immature Chrysoperla carnea (Neuroptera: Chrysopidae). Basic Appl. Ecol. 2, 35-44. doi: 10.1078/1439-1791-00034

Mohan, S., Ma, P. W. K., Williams, W. P., and Luthe, D. S. (2008). A naturally occurring plant cysteine protease possesses remarkable toxicity against insect pests and synergizes Bacillus thuringiensis toxin. PLoS ONE 3:e1786. doi: 10.1371/journal.pone.0001786

Ohlfrest, J. R., Jesse, L. C. H., Jurenka, R., and Obrycki, J. J. (2002). Stability of insecticidal CryIAb protein in transgenic Bt corn pollen exposed to UV irradiation. J. Kans. Entomol. Soc. 75, 48-51

Pardo-López, L., Soberón, M., and Bravo, A. (2013). Bacillus thuringiensis insecticidal three-domain Cry toxins: mode of action, insect resistance and consequences for crop protection. FEMS Microbiol. Rev. 37, 3-22. doi: 10.1111/j.1574-6976.2012.00341.x

Park, Y., Abdullah, M. A. F., Taylor, M. D., Rahman, K., and Adang, M. J. (2009). Enhancement of Bacillus thuringiensis Cry3Aa and Cry3Bb toxicities to coleopteran larvae by a toxin-binding fragment of an insect cadherin. Appl. Environ. Microbiol. 75, 3086-3092. doi: 10.1128/AEM. 00268-09

Pérez, C., Fernandez, L. E., Sun, J., Folch, J. L., Gill, S. S., Soberón, M., et al. (2005). Bacillus thuringiensis subsp. israelensis Cyt1Aa synergizes Cry11Aa toxin by functioning as a membrane-bound receptor. Proc. Natl. Acad. Sci. U.S. A. 102, 18303-18308. doi: 10.1073/pnas.0505494102

Phillips, A. M. (2008). Cry34Ab1, Cry35Ab1, Cry1F and PAT Protein Levels in Hybrid Maize TC1507, DAS-59122-7, MON 89034 x TC1507 x MON 88017 x DAS-59122-7 and a Conventional Cotnrol from the Monsanto 2006 Production Plan 06-01-52-04. DOW AgroSciences, LLC. Sub-report no. 061026.05. Available online: https://www.testbiotech.org/sites/default/files/Phillips_2008_ 0.pdf

Pigott, C. R., and Ellar, D. J. (2007). Role of receptors in Bacillus thuringiensis crystal toxin activity. Microbiol. Mol. Biol. Rev. 71, 255-281. doi: 10.1128/MMBR.00034-06

Pilacinski, W., Crawford, A., Downey, R., Harvey, B., Huber, S., Hunst, P., et al. (2011). Plants with genetically modified events combined by conventional breeding: an assessment of the need for additional regulatory data. Food Chem. Toxicol. 49, 1-7. doi: 10.1016/j.fct.2010.11.004

Poncet, S., Delécluse, A., Klier, A., Rapoport, G., Poncet, S., Delecluse, A., et al. (1995). Evaluation of synergistic interactions among the CryIVA, CryIVB, and CryIVD toxic components of Bacillus thuringiensis subsp israelensis crystals. J. Invertebr. Pathol. 66, 131-135. doi: 10.1006/jipa.1995.1075

Porcar, M., García-Robles, I., Domínguez-Escriba., L., and Latorre, A. (2010). Effects of Bacillus thuringiensis Cry1 Ab and Cry3Aa endotoxins on predatory
Coleoptera tested through artificial diet-incorporation bioassays. Bull. Entomol. Res. 100, 297-302. doi: 10.1017/S0007485309990290

Prihoda, K. R., and Coats, J. R. (2008). Aquatic fate and effects of Bacillus thuringiensis $\mathrm{Cry} 3 \mathrm{Bb} 1$ protein: toward risk assessment. Environ. Toxicol. Chem. 27, 793-798. doi: 10.1897/07-300.1

Promdonkoy, B., Promdonkoy, P., and Panyim, S. (2005). Co-expression of Bacillus thuringiensis Cry4Ba and Cyt2Aa2 in Escherichia coli revealed high synergism against Aedes aegypti and Culex quinquefasciatus larvae RID E-5617-2010 RID B-6024-2008. FEMS Microbiol. Lett. 252, 121-126. doi: 10.1016/j.femsle.2005.08.038

Qui, J. (2010). GM crop use makes minor pests major problem. Pesticide use rising as Chinese farmers fight insects thriving on transgenic crop. Nature. doi: 10.1038/news.2010.242

Ramírez-Suero, M., Valerio-Alfaro, G., Bernal, J. S., and Ramírez-Lepe, M. (2011). Synergisitic effect of chitinases and Bacillus thuringiensis israelensis sporetoxin complex against Aedes aegypti larvae. Can. Entomol. 143, 157-164. doi: 10.4039/n10-051

Raybould, A., Graser, G., Hill, K., and Ward, K. (2012). Ecological risk assessments for transgenic crops with combined insect - resistance traits: the example of Bt11 x MIR604 maize. J. Appl. Entomol. 136, 27-37. doi: 10.1111/j.14390418.2010.01601.x

Raymond, B., Johnston, P. R., Wright, D. J., Ellis, R. J., Crickmore, N., and Bonsall, M. B. (2009). A mid-gut microbiota is not required for the pathogenicity of Bacillus thuringiensis to diamondback moth larvae. Environ. Microbiol. 11, 2556-2563. doi: 10.1111/j.1462-2920.2009.01980.x

Reetz, J. E., Zühlke, S., Spiteller, M., and Wallner, K. (2011). Neonicotinoid insecticides translocated in guttated droplets of seed-treated maize and wheat: a threat to honeybees? Apidologie 42, 596-606. doi: 10.1007/s13592-011-0049-1

Regev, A., Keller, M., Strizhov, N., Sneh, B., Prudovsky, E., Chet, I., et al. (1996). Synergistic activity of a Bacillus thuringiensis delta-endotoxin and a bacterial endochitinase against Spodoptera littoralis larvae. Appl. Environ. Microbiol. 62, 3581-3586.

Ricroch, A., Bergé, J. B., and Kuntz, M. (2010). Is the German suspension of MON810 maize cultivation scientifically justified? Transgenic Res. 19, 1-12. doi: 10.1007/s11248-009-9297-5

Rincon-Castro, M. C., Barajas-Huerta, J., and Ibarra, J. E. (1999). Antagonism between Cry1Ac1 and Cyt1A1 toxins of Bacillus thuringiensis. Appl. Environ. Microbiol. 65, 2049-2053

Rodrigo-Simón, A., de Maagd, R. A., de Avilla, C., Bakker, P. L., Molthoff, J., González- Zamora, J. E., et al. (2006). Lack of Detrimental Effects of Bacillus thuringiensis Cry Toxins on the Insect Predator Chrysoperla carnea: a Toxicological, histopathological, and biochemical analysis. Appl. Environ. Microbiol. 72, 595-1603. doi: 10.1128/AEM.72.2.1595-1603.2006

Romeis, J., Bartsch, D., Bigler, F., Candolfi, M. P., Gielkens, M. M. C., Hartley, S. E., et al. (2008). Assessment of risk of insect-resistant transgenic crops to nontarget arthropods. Nat. Biotechnol. 26, 203-208. doi: 10.1038/nbt1381

Romeis, J., Dutton, A., and Bigler, F. (2004). Bacillus thuringiensis toxin (CrylAb) has no direct effect on larvae of the green lacewing Chrysoperla carnea (Stephens'Neuroptera: Chrysopidae). J. Insect Physiol. 50, 175-183. doi: 10.1016/j.jinsphys.2003.11.004

Romeis, J., McLean, M. A., and Shelton, A. M. (2013). When bad science makes good headlines: Bt maize and regulatory bans. Nat. Biotechnol. 31, 386-387. doi: $10.1038 /$ nbt.2578

Romeis, J., Meissle, M., and Bigler, F. (2006). Transgenic crops expressing Bacillus thuringiensis toxins and biological control. Nat. Biotechnol. 24, 63-71. doi: $10.1038 /$ nbt1 180

Rosi-Marshall, E. J., Tank, J. L., Royer, T. V., Whiles, M. R., Evans-White, M., Chambers, C., et al. (2007). Toxins in transgenic crop byproducts may affect headwater stream ecosystems. Proc. Natl. Acad. Sci. U.S.A. 104, 16204-16208. doi: $10.1073 /$ pnas.0707177104

Sanchis, V. (2011). From microbial sprays to insect-resistant transgenic plants: history of the biopesticide Bacillus thuringiensis. A review. Agron. Sustain. Dev. 31, 217-231. doi: 10.1051/agro/2010027

Sansinenea, E. (2012). Bacillus thuringiensis Biotechnology. Dordrecht; Heidelberg; London; New York, NY: Springer.

Schmidt, J. E. U., Braun, C. U., Whitehouse, L. P., and Hilbeck, A. (2009). Effects of Activated Bt Transgene Products (Cry1 Ab, Cry3Bb) on Immature Stages of the Ladybird Adalia bipunctata in Laboratory ecotoxicity testing. Arch. Environ. Contam. Toxicol. 56, 221-228. doi: 10.1007/s00244-008-9191-9 
Schnepf, E., Crickmore, N., Van Rie, J., Lereclus, D., Baum, J., Feitelson, J., et al. (1998). Bacillus thuringiensis and its pesticidal crystal proteins. Microbiol. Mol. Biol. Rev. 62, 775-806.

Sharma, P., Nain, V., Lakhanpual, S., and Kumar, P. A. (2010). Synergistic activity between Bacillus thuringiensis $\mathrm{Cry} 1 \mathrm{Ab}$ and Cryl Ac toxins against maize stem borer (Chilo partellus Swinhoe). Lett. Appl. Microbiol. 51, 42-47. doi: 10.1111/j.1472-765x.2010.02856.x

Shu, Y., Zhang, Y., Cheng, M., Zeng, H., and Wang, J. (2015). Multilevel assessment of Cryl Ab Bt-maize straw return affecting the earthworm '. Chemosphere 137, 59-69. doi: 10.1016/j.chemosphere.2015.05.038

Smouse, D., and Nishiura, J. (1997). A Bacillus thuringiensis delta-endotoxin induces programmed cell death in mosquito larvae. Cell Death Differ. 4, 560-569.

Soberón, M., Gill, S. S., and Bravo, A. (2009). Signaling versus punching hole: how do Bacillus thuringiensis toxins kill insect midgut cells? Cell. Mol. Life Sci. 66, 1337-1349. doi: 10.1007/s00018-008-8330-9

Soberón, M., Pardo-López, L., López, I., Gómez, I., Tabashnik, B., and Bravo, A. (2007). Engineering modified Bt toxins to counter insect resistance. Science 318, 1640-1642. doi: 10.1126/science. 1256132

Soberon, M., Rodriguez-Almazan, C., Munoz-Garay, C., Pardo-Lopez, L., Porta, H., and Bravo, A. (2012). Bacillus thuringiensis Cry and Cyt mutants useful to counter toxin action in specific environments and to overcome insect resistance in the field. Pesticide Biochem. Physiol. 104, 111-117. doi: 10.1016/j.pestbp.2012.05.003

Song, P., Wang, Q., Nangong, Z., Su, J., and Ge, D. (2012). Identification of Henosepilachna vigintioctomaculata (Coleoptera: Coccinellidae) midgut putative receptor for Bacillus thuringiensis insecticidal Cry7Ab3 toxin. J. Invertebr. Pathol. 109, 318-322. doi: 10.1016/j.jip.2012. 01.009

Stephens, E. J., Losey, J. E., Allee, L. L., Di Tommaso, A., Bodner, C., and Breyre, A. (2012). The impact of Cry3Bb Bt-maize on two guilds of beneficial beetles. Agric. Ecosyst. Environ. 156, 72-81. doi: 10.1016/j.agee.2012.05.002

Stillwell, L., and Silvanovich, A. (2007). Assessment of Cry1A.105, Cry2Ab2, Cry3Bb1, and CP4 EPSPS Protein levels in the Combined Trati Corn Product MON $89034 \times$ TC1507 x MON $88017 \times$ DAS-59122-7 produced in U.S. Field Trials during 2006. Monsanto Company, Sub-report no. MSL0021070. Available online at: https://www.testbiotech.org/sites/default/files/Stillwell_ Silvanowich_2008.pdf

Storer, N. P., Thompson, G. D., and Head, G. P. (2012). Application of pyramided traits against Lepidoptera in insect resistance management for Bt crops. GM Crops Food 3, 3-9. doi: 10.4161/gmcr.20945

Tabashnik, B. E. (1992). Evaluation of synergism among Bacillus thuringiensis toxins. Appl. Environ. Microbiol. 58, 3343-3346.

Tabashnik, B. E., Brévault, T., and Carrière, Y. (2013). Insect resistance to Bt crops: lessons from the first billion acres. Nat. Biotechnol. 31, 510-521. doi: $10.1038 /$ nbt.2597

Tang, J. D., Shelton, A. M., Van Rie, J., De Roeck, S., Moar, W. J., Roush, R. T., et al. (1996). Toxicity of Bacillus thuringiensis spore and crystal protein to resistant diamondback moth (Plutella xylostella). Appl. Environ. Microbiol. 62, 564-569.

Then, C. (2010). Risk assessment of toxins derived from Bacillus thuringiensis synergism, efficacy, and selectivity. Environ. Sci. Pollut. Res. Int. 17, 791-797. doi: 10.1007/s11356-009-0208-3

Then, C. (2013). Hohe Rückstandsmengen von Glyphosat bei Sojabohnen in Argentinien. Testbiotech Hintergrundbericht. Available online at: https://www. testbiotech.org/sites/default/files/TBT_Hintergrund_Glyphosat_Argentina. pdf

United States Department of Agriculture (USDA) and Economic Research Service (ERS) (2014). Adoption of Genetically Engineered Crops in the U.S. Available online at: http://www.ers.usda.gov/data-products/adoption-ofgenetically-engineered-crops-in-the-us/recent-trends-in-ge-adoption.aspx

Vachon, V., Laprade, R., and Schwartz, J. L. (2012). Current models of the mode of action of Bacillus thuringiensis insecticidal crystal proteins: a critical review. J. Invertebr. Pathol. 111, 1-12. doi: 10.1016/j.jip.2012.05.001

van der Hoeven, M. (2014). Bacillus Thuringiensis Toxins: Their mode of Action and the Potential Interaction between them. Commissioned and published by: COGEM (The Netherlands Commission on Genetic Modification) - (CGM 2014-02)

van Frankenhuyzen, K. (2009). Insecticidal activity of Bacillus thuringiensis crystal proteins. J. Invertebr. Pathol. 101, 1-16. doi: 10.1016/j.jip.2009.02.009 van Frankenhuyzen, K. (2013). Cross-order and cross-phylum activity of Bacillus thuringiensis pesticidal proteins. J. Invertebr. Pathol. 114, 76-85. doi: 10.1016/j.jip.2013.05.010

van Frankenhuyzen, K., and Nystrom, C. (2002). The Bacillus Thuringiensis Toxin Specificity Database. Available online at: http://www.glfc.cfs.nrcan.gc.ca/ bacillus (Accessed September 1, 2015).

Waltz, E. (2009a). Battlefields. Nature 461, 27-32. doi: 10.1038/461027a

Waltz, E. (2009b). Under wraps. Nat. Biotechnol. 27, 880-882. doi: $10.1038 /$ nbt1009-880

Watanabe, Y., Iwaki-Egawa, S., Mizukoshi, H., and Fujimoto, Y. (1995). Identification of an alanine aminopeptidase in human maternal serum as a membrane-bound aminopeptidase. Biol. Chem. 376, 397-400. doi: 10.1515/bchm3.1995.376.7.397

Whalon, M. E., and Wingerd, B. A. (2003). Bt: Mode of action and use. Arch. Insect Biochem. Physiol. 54, 200-211. doi: 10.1002/arch.10117

Wickson, F., Bøhn, T., Wynne, B., Hilbeck, A., and Funtowicz, S. (2013). Sciencebased risk assessment requires careful evaluation of all studies. Nat. Biotechnol. 31, 1077-1078. doi: 10.1038/nbt.2761

Wirth, M. C., Jiannino, J. A., Federici, B. A., and Walton, W. E. (2004), Synergy between toxins of Bacillus thuringiensis subsp. israelensis and Bacillus sphaericus. J. Med. Entomol. 41, 935-941. doi: 10.1603/0022-2585-41.5.935

Wu, D., Chang, F. N., Wu, D., and Chang, F. N. (1985). Synergism in mosquitocidal activity of $26-\mathrm{kDa}$ and $65-\mathrm{kDa}$ proteins from Bacillus thuringiensis subsp israelensis crystal. FEBS Lett. 190, 232-236. doi: 10.1016/0014-5793(85)81290-4

Wu, D., Johnson, J. J., and Federici, B. A. (1994). Synergism of mosquitocidal toxicity between CytA and CryIVD proteins using inclusions produced from cloned genes of Bacillus thuringiensis. Mol. Microbiol. 13, 965-972. doi: 10.1111/j.1365-2958.1994.tb00488.x

Yunus, F. N., Makhdoom, R., and Raza, G. (2011). Synergism between Bacillus thuringiensis toxins Cry1Ac and Cry2Aa against Earias vitella (Lepidoptera). Pak. J. Zool. 43, 575-580.

Zemkova Rovenska, G., Zemek, R. J., Schmidt, E. U., and Hilbeck, A. (2005). Effects of transgenic Bt-eggplant expressing Cry3Bb toxin on host plant preference of Tetranychus urticae and prey preference of its predator Phytoseiulus persimilis (Acari: Tetranychidae, Phytoseiidae). Biol. Control 33, 293-300. doi: 10.1016/j.biocontrol.2005.03.017

Zhang, G. F., Wan, F. H., Liu, W. X., and Guo, J. Y. (2006b). Earlyinstar response to plant-delivered Bt-toxin in a herbivore (Spodoptera litura) and a predator (Propylea japonica). Crop Protect. 25, 527-533. doi: 10.1016/j.cropro.2005.08.008

Zhang, G. F., Wan, F. H., Lövei, G., Liu, W. X., and Guo, J. Y. (2006c). Transmission of Bt toxin to the predator Propylea japonica (Coleoptera: Coccinellidae) through its aphid prey feeding on transgenic Bt cotton. Environ. Entomol. 35, 143-150. doi: 10.1603/0046-225X-35.1.143

Zhang, S. Y., Li, D. M., Cui, J., and Xie, B. Y. (2006d). Effects of Bt-toxin CrylAc on Propylea japonica Thunberg (Col., Coccinellidae) by feeding on Bt-treated Bt-resistant Helicoverpa armigera (Hübner) (Lep., Noctuidae) larvae. J. Appl. Entomol. 130, 206-212. doi: 10.1111/j.1439-0418.2006.01049.x

Zhang, X., Candas, M., Griko, N. B., Rose-Young, L., and Bulla, L. A. (2005). Cytotoxicity of Bacillus thuringiensis Cryl Ab toxin depends on specific binding of the toxin to the cadherin receptor BT-R1 expressed in insect cells. Cell Death Differ. 12, 1407-1416. doi: 10.1038/sj.cdd.4401675

Zhang, X., Candas, M., Griko, N. B., Taussig, R., and Bulla, L. A. Jr. (2006a). A mechanism of cell death involving an adenylyl cyclase/PKA signaling pathway is induced by the Cry1 Ab toxin of Bacillus thuringiensis. Proc. Natl. Acad. Sci. U.S.A. 103, 9897-9902. doi: 10.1073/pnas.0604017103

Zhang, X., Li, Y., Romeis, J., Yin, X., Wu, K., and Peng, Y. (2014). Use of a pollen-based diet to expose the ladybird beetle Propylea japonica to insecticidal proteins. PLoS ONE 9:e85395. doi: 10.1371/journal.pone.0085395

Conflict of Interest Statement: The authors declare that the research was conducted in the absence of any commercial or financial relationships that could be construed as a potential conflict of interest.

Copyright (๑) 2015 Hilbeck and Otto. This is an open-access article distributed under the terms of the Creative Commons Attribution License (CC BY). The use, distribution or reproduction in other forums is permitted, provided the original author(s) or licensor are credited and that the original publication in this journal is cited, in accordance with accepted academic practice. No use, distribution or reproduction is permitted which does not comply with these terms. 